\title{
Assessing the *discriminative properties of response -reinforcer relations using concurrent schedules of reinforcement
}

Josue P. Keely

West Virginia University

Follow this and additional works at: https://researchrepository.wvu.edu/etd

\section{Recommended Citation}

Keely, Josue P., "Assessing the *discriminative properties of response -reinforcer relations using concurrent schedules of reinforcement" (1999). Graduate Theses, Dissertations, and Problem Reports. 3153.

https://researchrepository.wvu.edu/etd/3153

This Dissertation is protected by copyright and/or related rights. It has been brought to you by the The Research Repository @ WVU with permission from the rights-holder(s). You are free to use this Dissertation in any way that is permitted by the copyright and related rights legislation that applies to your use. For other uses you must obtain permission from the rights-holder(s) directly, unless additional rights are indicated by a Creative Commons license in the record and/ or on the work itself. This Dissertation has been accepted for inclusion in WVU Graduate Theses, Dissertations, and Problem Reports collection by an authorized administrator of The Research Repository @ WVU.

For more information, please contact researchrepository@mail.wvu.edu. 


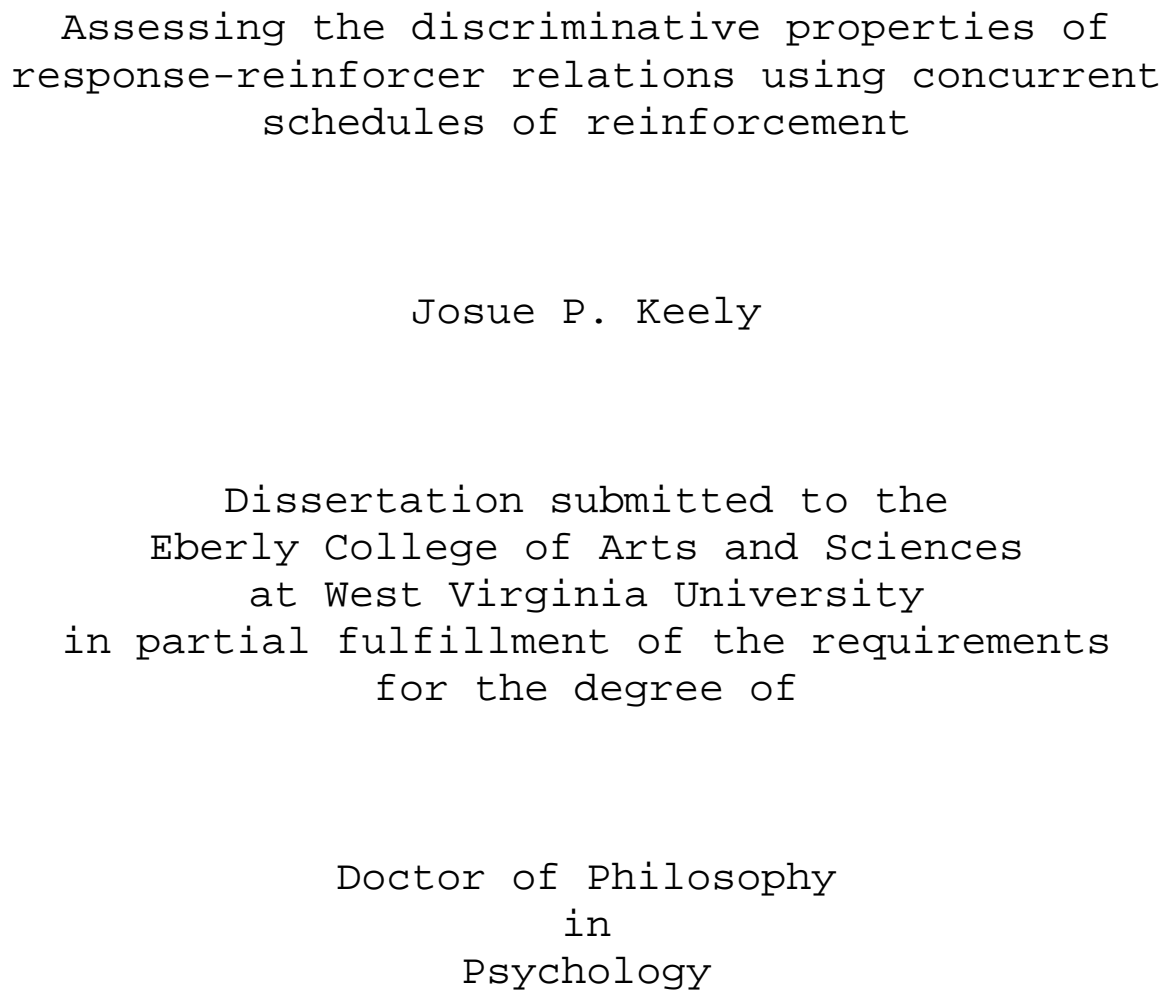

Kennon A. Lattal, Ph.D., Chair

Elbert D. Glover, Ph.D.

Michael Perone, Ph.D.

David W. Schaal, Ph.D.

Anne Watson, Ph.D.

Department of Psychology 


\begin{abstract}
Assessing the discriminative properties of response-reinforcer relations using concurrent schedules of reinforcement

Josue P. Keely
\end{abstract}

The discriminative properties of schedules of reinforcement have been assessed by making a choice response conditional upon some aspect of the schedule that produced the choice component. The discriminative properties of concurrent schedules of reinforcement and the effect of disruptions in the response-reinforcer relation were investigated using conditional-discrimination procedures. In the first experiment, choice components were produced by responding to one of two variable-interval (VI) schedules. Disruptions in the temporal contiguity between a VI response and a choice component were introduced by arranging a percentage of choice components according to a variable-time schedule. Choice responding was a function of the response that produced the choice component. Delays of up to $0.5 \mathrm{~s}$ resulted in responding that corresponded to the last VI response made.

In the second experiment, the delay between a VI response and choice component was controlled for by arranging choices according to concurrent VI and differential-reinforcement-of-other-behavior (DRO) schedules. Choice responding was a function of which schedule arranged the choice component. Varying the DRO value resulted in increased choice accuracy at shorter (0.25 to $2.00 \mathrm{~s})$ delays and decreased accuracy at delays of greater than $2.00 \mathrm{~s}$. These results indicate that concurrent schedules of reinforcement can serve a discriminative function and that the discriminative properties of response-reinforcer relations are a function of the temporal contiguity between a response and a stimulus change. 


\section{ACKNOWLEDGEMENTS}

I would like to thank all of the members of my dissertation committee for their patience and their suggestions. Collectively, they have made this a stronger document. I would like to thank Dr. Anne Watson for her work since I first asked her to serve on my thesis committee. I wish to thank Dr. Michael Perone for his insight and his support during this process. His encouragement was appreciated. I thank Dr. David Schaal for getting me into a lab from the first day I arrived at WVU. He helped shape the skills necessary to conduct competent research. Thank you to Dr. Elbert Glover for introducing me to another area of research and for help in preparing me for life outside the animal lab. Finally, I would like to thank Dr. Andy Lattal. He has been my role model in and out of the laboratory. He expressed confidence in me throughout my tenure at WVU and has helped me to achieve what I have accomplished thus far.

I also wish to thank my wife, Heather Cahill. Her

support has made this document possible. She has always stood by me and has made innumerable sacrifices so that I might reach this point. I will always be grateful. 


\section{LIST OF FIGURES}

Figure 1: Schematic of work panel..............22

Figure 2: Response rates to the VI keys for the first

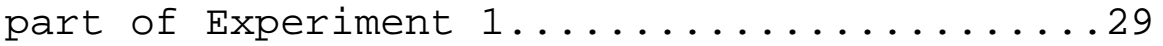

Figure 3: Percent correct choice responses for the first

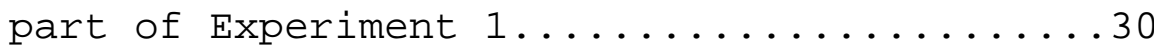

Figure 4: Total number of each type of error for the first part of Experiment 1...............

Figure 5: Response rates to the VI keys for the second part of Experiment $1 \ldots \ldots \ldots \ldots \ldots \ldots \ldots$

Figure 6: Percent correct choices for the second part of

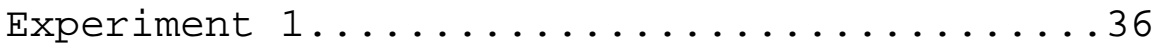

Figure 7: Percentage of choice responses that corresponded to the last VI peck made on VTproduced choices for Experiment 1........37

Figure 8: Percentage of bottom-key choices for the last six sessions of Experiment 1..............

Figure 9: Response rates to the VI keys and the number of 2-s pauses per minute for Experiment 2..47

Figure 10: Percent correct choice responses for Experiment $2 \ldots \ldots \ldots \ldots \ldots \ldots \ldots$

Figure 11: Total number of each type of error for

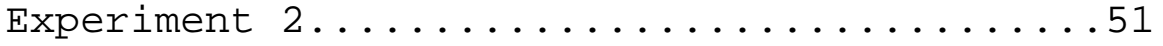

Figure 12: Percent correct choice responses for the DROprobe sessions of Experiment 2 plotted as a function of DRO value.................52

Figure 13: Percent correct choice responses averaged across subjects for the DRO-probe sessions of Experiment 2 plotted as a function of DRO

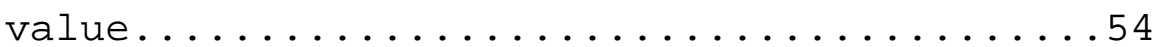




\section{LIST OF TABLES}

Table 1: List of conditions for Experiment 1......26 


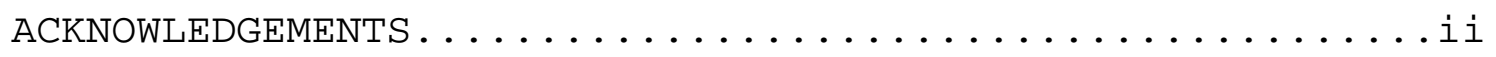

LIST OF FIGURES............................

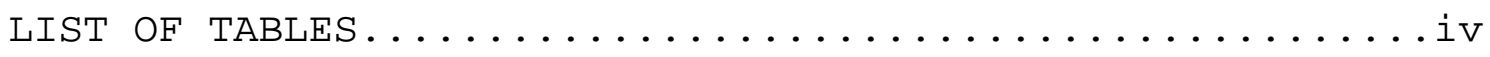

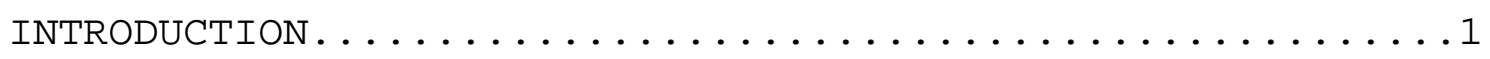

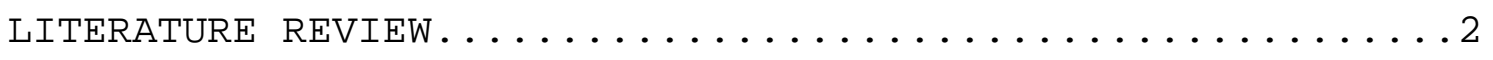

EXPERIMENT 1

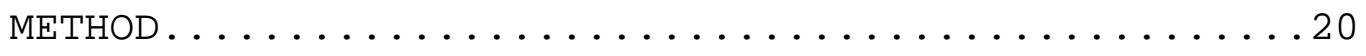

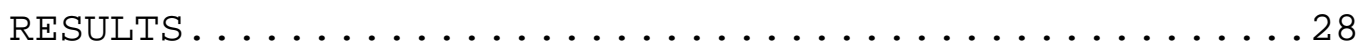

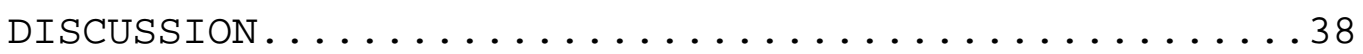

EXPERIMENT 2

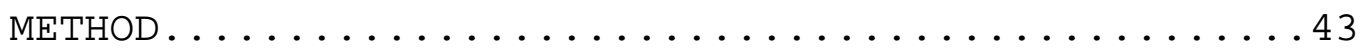

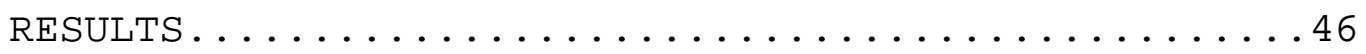

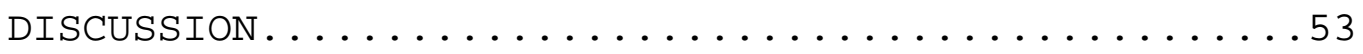

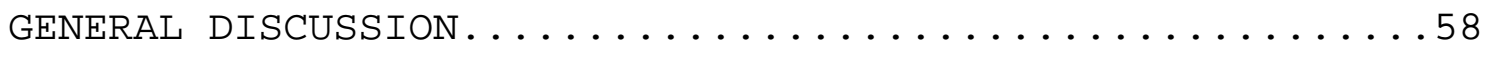

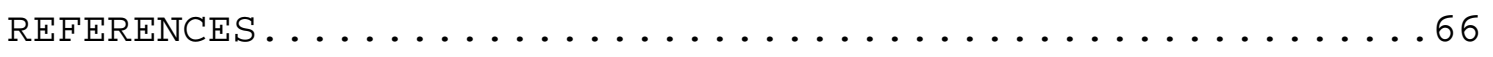

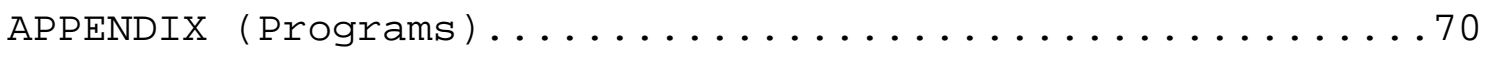

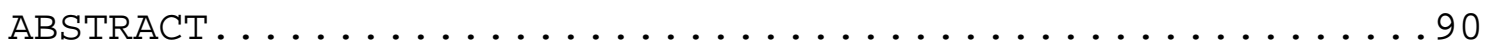

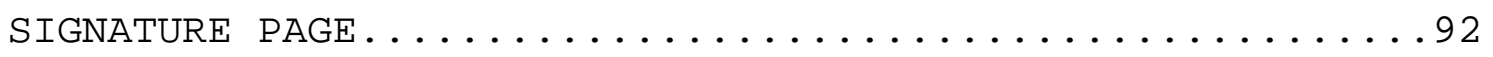




\section{Introduction}

It has been suggested that the discriminative properties of response-reinforcer relations generated by schedules of reinforcement influence both the rate of responding and its distribution among alternatives (Alsop \& Davison, 1992; Jones \& Davison, 1998; Killeen, 1978, 1981; Lattal, 1975, 1979, 1981). A conditional discrimination procedure makes it possible to manipulate aspects of response-reinforcer relations and thereby to elucidate the conditions under which they can serve as discriminative stimuli.

The conditions necessary for response-reinforcer relations to serve as discriminative stimuli have not yet been established. Specifically, in previous studies of such discriminative stimuli, the dependency between a response and a reinforcer typically has been confounded with temporal contiguity. Only Warner (1990) attempted to manipulate the response-reinforcer contingency while keeping the temporal contiguity between the two events constant. The proposed experiments attempted to disentangle the discriminative effects of contingency and contiguity between a response and reinforcer. In the first experiment contiguity was manipulated while the response-reinforcer dependency remained constant and in the second experiment both contingency and contiguity were varied. 


\section{Literature Review}

\section{Direct and Indirect Effects of Schedule Performance}

Research on schedule performance has focused primarily on the ways in which contingencies of reinforcement or punishment modify rates or topographies of behavior. These dimensions of responding are determined by the parameters of the schedule and may involve the rate of a response, the temporal distribution of responding or inter-response times (IRTs), the dynamics of the response, as in its location or force, or the allocation of behavior between two or more alternatives. It has been suggested that changes in behavior as a function of contingency manipulations are an index of an organism's knowledge regarding the effective schedule: "When behavior adapts to a reinforcement contingency, thus conforming more closely to that required for reinforcement, we can say that the organism in a sense 'knows' something about the contingency, even though it might be unable to describe verbally what it knows" (Shimp, 1983, p. 61). Shimp designated this type of knowing as "tacit knowledge", or "'knowing how' as opposed to 'knowing that'."

Behavior that is sensitive to changes in contingencies (i.e., changes as an orderly function of schedule changes), however, need not imply knowledge by the organism. Gewirtz (1997) suggested that orderly changes in responding indicate that a 
subject has detected the relevant parameters. Schedule performance sometimes is assumed to be an index of discrimination on the part of the behaving organism. However, changes in the rate or pattern of responding that are specified by a particular schedule are not an appropriate measure of the discriminability of response-reinforcer relations. The effects that schedules of reinforcement exert have been more precisely described as direct and indirect. Direct effects are those aspects of a schedule that must be met for a consequence to occur (Zeiler, 1977). Indirect effects refer to the patterns and topographies of behavior not explicitly required by a schedule but which develop with exposure to the schedule. For example, the function relating responding to the rate of reinforcement is determined by the programmed contingencies but also by the temporal distribution of responding. These latter characteristics of schedules result in behavior patterns and relations between behavior and it consequences that are free to vary.

One method used by some investigators to separate the direct and indirect effects of schedules of reinforcement is to assess relative changes in response rates as a function of stimulus changes or schedule manipulations (Lattal, 1973, 1974; Zeiler, 1976). For instance, Lattal (1974) trained keypecking in pigeons using variable-interval (VI) 60- or 100-s schedules of food delivery. The schedule of reinforcement was then changed from a 
VI to a variable-time (VT) 60- or 100-s schedule. This created a situation in which the same number of reinforcers was delivered at approximately the same time but responding no longer was necessary. Finally, in subsequent conditions, different percentages of reinforcers were delivered independently of responding while maintaining the same average inter-reinforcer interval (IRI). Keypecking was an increasing function of the percentage of reinforcers delivered response-dependently. These data indicate that behavior was sensitive to changes in the schedules of reinforcement. In addition, the different responsereinforcer relations may have been discriminated.

The procedure described above provides only suggestive evidence of the discriminative properties of schedules of reinforcement because it is impossible to differentiate behavior changes that are a result of direct effects from those that are a result of the indirect effects of schedules. Lattal (1975, 1981) and Nussear and Lattal (1983) have observed that using rate as a measure of discrimination entangles the direct, rate-controlling effects of reinforcement with the indirect, discriminativestimulus effects.

One solution to the analysis of the discriminative properties of schedules of reinforcement is to arrange a procedure in which some aspect of the programmed contingencies and/or the behavior maintained by the contingencies serves as the 
sample in a symbolic-matching-to-sample, or conditionaldiscrimination, task. In such a procedure, one schedule parameter, such as fixed-ratio (FR) length is manipulated so that at least two different schedules are effected at different times. During a choice component, the "correct" or reinforced response is dependent or conditional upon the most recent sample stimulus (i.e., the last effective schedule). Such a procedure forces the indirect variables in schedules of reinforcement to function as direct variables. Some aspect of the behavior generated by the schedule that produced a matching or choice component is assigned to be a discriminative stimulus for responding during the choice. An example of a procedure in which schedules of reinforcement serve as discriminative stimuli was reported by Pliskoff and Goldiamond (1966). Pigeons were trained to peck the center key of a three key array. Completion of one of two FR schedules (FR 25 or FR 75) darkened the center key and illuminated the two side keys white. If the completion of the smaller FR requirement resulted in the choice component then a response to the left key resulted in $3-4 \mathrm{~s}$ access to grain. If the completion of the larger FR resulted in the choice component, a response to the right key was reinforced. Incorrect choice responses were followed immediately by the next sample component. Responding during choice components was accurate when the difference between the larger and smaller FR schedules was great. 
As the two FRs were made more similar, choice accuracy decreased. This procedure allowed the discriminative properties of FR schedules to be separated from the direct, rate increasing effects of reinforcement.

There are many aspects of schedule performance that may serve as discriminative stimuli. Conditional discrimination procedures similar to the one described above have been used to study the discriminative properties of temporal patterns of responding (Reynolds, 1966; Shimp, 1981, 1983), of stimulus duration (Stubbs, 1968, 1976), of response-dependent and response-independent contingencies (Killeen, 1978, 1981; Lattal, 1975, 1979; Nussear \& Lattal, 1983; Warner 1990), of delays to reinforcement (Warner, 1990) and of concurrent schedules of reinforcement (Alsop \& Davison, 1991, 1992; Jones \& Davison, 1998) .

Discriminative Properties of Response-Reinforcer Relations The discriminative properties of the response-reinforcer relations generated by schedules of response-dependent and response-independent food delivery have been examined in detail (see previous discussion of Lattal 1974). Changes in response rates in Lattal's studies and others like them, may reflect the influence of the direct, rate-decreasing effects of responseindependent reinforcement, the discriminative properties of the response-reinforcer relations, or a combination of the two. 
However, the confounding of direct and indirect effects by employing concurrent schedules of response-dependent and response-independent reinforcement does not elucidate the indirect effects of schedules of reinforcement.

Using pigeons as subjects, Lattal (1975), employed a procedure where completion of either a differentialreinforcement-of-other-behavior (DRO) or a differentialreinforcement-of-low-rates (DRL) schedule requirement produced a choice component. Keypecking or pausing on a single key produced choice components according to a mixed DRO 10-s DRL 10-s schedule. When completion of the DRO schedule requirement yielded a choice component a response to a green side key resulted in 3-s access to food. Red side key choice responses were reinforced when the completion of the DRL requirement produced the choice component. The discriminative properties of the two responsereinforcer relations controlled choice responding across reversals and with the imposition of brief delays.

Utilizing a similar procedure Killeen (1978, 1981) investigated the discriminative properties of response-reinforcer relations generated by delays to reinforcement of shorter durations. Pigeon's keypecks had a 0.05 probability of turning off a center key and illuminating two side keys. A computer simultaneously generated responses at the same rate as the pigeon. These pseudo-pecks also had a 0.05 probability of 
producing a choice component. This schedule arrangement resulted in a choice component after an average of 20 keypecks and an equal number of response-independent choice components with a similar temporal distribution. A right choice response was reinforced when the choice component was the result of keypecking. This was defined as choosing "I caused it." Left choices were reinforced when the choice component was responseindependent. Subjects accurately identified whether a choice was caused by them or the computer provided that the time between the last response and a response-independent choice component was at least $0.8 \mathrm{~s}$. When obtained delays were shorter, the probability of a false alarm, that is choosing "I caused it" when the component was response-independent, increased rapidly. These data were similar to those of Lattal (1975) in that both studies demonstrated that response-reinforcer relations and temporal disruptions in response-reinforcer contiguity are discriminable. Warner (1990) employed a similar conditional discrimination procedure to assess the discriminability of response-dependent but delayed reinforcement versus response-independent reinforcement. A correct choice was dependent upon whether a tandem VI 30-s DRO 2-s or a yoked tandem VT 30-s FT 2-s schedule produced a choice component. Responding during choice components was not reliably a function of which schedule had produced the choice. These findings are in contrast to those of Lattal and 
Killeen. One potentially important difference in Warner's procedure from Lattal's and Killeen's experiments was the fact that all reinforcers were not contiguous with a response whereas Lattal and Killeen had delays between a response and reinforcer only when the reinforcer was independent of behavior. This resulted in their manipulating two variables simultaneously. The studies of Lattal (1975, 1979, 1981), Killeen (1978, 1981), and Warner (1990) may be considered as investigating the discriminability of the source of reinforcement. Each arranged schedules of food delivery such that during one component the source of reinforcement was keypecking and in the other component the "source" of reinforcement was any behavior or any behavior other than keypecking. Choice responding therefore was differentially reinforced as a function of the source of the previous reinforcer. Discriminative Properties of Reinforcement Sources in Concurrent $\underline{\text { Schedules }}$

Concurrent schedules arrange response-reinforcer relations similar to those produced by the schedules described above (Lattal, 1975, 1979; Killeen, 1978, 1981). That is, the contiguity between a response and a reinforcer is maintained. It has been suggested that behavior allocated to concurrent alternatives is, at least in part, a function of the discriminability of the different response-reinforcer relations 
(Alsop \& Davison, 1992; Davison \& McCarthy, 1988), or sources of reinforcement. However, the discriminative properties of the response-reinforcer relations generated by concurrent schedules have received little attention and the results of the existing studies are ambiguous.

Concurrent schedules of reinforcement arrange two simultaneous sources of reinforcement. Though not necessary, different stimuli and, in a two-key concurrent-schedule procedure, different operanda are correlated with each schedule of reinforcement, which may enhance schedule discriminability. In addition, a changeover response from one schedule to the other typically is employed to increase the discriminability of the different schedules (see Davison \& McCarthy, 1988 for a review).

There are few studies in which the discriminative properties of component schedules of a concurrent schedule of reinforcement have been investigated. The discriminative properties of concurrent schedules have been related to the matching relation, that is, the finding that the rate of responding to a schedule relative to all other behavior roughly corresponds to the rate of reinforcement obtained from that schedule relative to all other concurrently available schedules of reinforcement (see Davison \& McCarthy, 1988 for a review). For example, Alsop and Davison (1992) used a changeover-key (Findley, 1958) procedure to assess the discriminability of concurrent VI 20-s VI 20-s schedules and 
concurrent VI 14-s VI 33-s schedules of reinforcement in pigeons. Under the changeover-key procedure, responses to a blue changeover key changed the illumination intensity of a white main key on which reinforcers were arranged according to the concurrent VI schedule pairs listed above. Responding on the main key initiated a symbolic-matching-to-sample procedure. After an interval elapsed, a VI response extinguished the main key and the changeover key and illuminated two red choice keys. A response to the left choice key was reinforced according to a 0.5 probability if the VI schedule correlated with the dimmer intensity had produced the choice component. A response to the right choice key was reinforced according to a 0.5 probability if the VI schedule correlated with the brighter intensity had produced the choice component. Measures of discriminability associated with the concurrent schedules indicated that the schedules associated with each concurrent pair were discriminable.

Jones and Davison (1998) employed a procedure similar to that of Alsop and Davison (1992). A changeover-key procedure (Findley, 1958) was used and reinforcers consisted of $0.3-\mathrm{s}$ access to grain. Responding on a changeover key alternated two schedule-correlated stimuli on a second response key. The concurrent schedules were correlated with different intensities of yellow light. A choice component in which two side keys were illuminated red and green was initiated after the delivery of a 
reinforcer. A response to the red choice was reinforced intermittently if the concurrent schedule correlated with the brighter intensity of yellow had produced the choice component and a response to the green choice was reinforced if the concurrent schedule associated with the lighter intensity of yellow had produced the choice component. Incorrect choices were followed by a 3-s blackout and then the onset of a correction procedure during which the response key was lit the intensity of yellow that preceded the choice component. The first response on the main key produced a reinforcer followed by a choice component identical to the previous one. This continued until a correct choice response occurred. The length of the reinforcer following a VI response was increased from $0.3 \mathrm{~s}$ to 1.0 or $2.0 \mathrm{~s}$ and the ratio of reinforced correct choice responses was varied such that a correct response to the red or green choice had a higher probability of reinforcement across conditions. Choice was accurate across conditions with few red choice responses occurring when components were produced by the VI correlated with the dim stimulus and vice versa. The ratio of reinforced correct red and green choice responses biased responding toward the choice with the higher probability of being reinforced.

The two studies described above have been offered as evidence of the discriminability of concurrent schedules of reinforcement and have been used to further a discrimination- 
based account of concurrent schedule performance. Specifically, it has been suggested that matching and deviations from matching are a function of decreases in discriminability of the component schedules. Davison and his colleagues' measure of discriminability indicates pigeons accurately identified the source of reinforcement, that is, which schedule initiated a choice component (Alsop \& Davison, 1992; Jones \& Davison, 1998). In both of Davison's studies cited above, each concurrent schedule of reinforcement was correlated with a stimulus of a different intensity. One of the stimuli was presented either immediately prior to a choice component or followed by a delay ranging from 1.5 to $10.0 \mathrm{~s}$ in Alsop and Davison (1992) or from 0.3 to $2.0 \mathrm{~s}$ in Jones and Davison (1998). Performance on a symbolic-matching-to-sample procedure using the same stimuli resulted in similar findings (Alsop \& Davison, 1992). It is possible that the two light intensities served as the discriminative stimuli and that changes in the discriminability measure were a function of changes in the frequency with which each stimulus was followed by food. The authors therefore failed to provide conclusive evidence that response-reinforcer relations as such served as discriminative stimuli. As a result they have not demonstrated that discrimination of response-reinforcer relations is necessary for the development of typical concurrent schedule performance. Concurrent schedules dictate that some 
stimulus, either interoceptive or exteroceptive, will be correlated with the two schedules. However, the use of external correlated stimuli that are unnecessary in concurrent schedules, precludes the assessment of whether response-reinforcer relations independently serve a discriminative function.

The work of Alsop and Davison (1992) and Jones and Davison (1998), like that of Lattal (1975, 1979, 1981) and Killeen (1978, 1981), may be considered as an investigation of the discriminability of the source of reinforcement. In each of the former two experiments, the source of reinforcement was varied by manipulating temporal contiguity between responding and hopper presentation. In the latter studies the source was varied by manipulating the schedule itself and the exteroceptive stimuli correlated with each schedule. Signal Detection As a Means of Assessing Response-Reinforcer Discriminations

Schedules of reinforcement occurring in natural settings rarely arrange for reinforcers to be distributed evenly among response alternatives. Rather, different sources have different probabilities of producing a reinforcer. In conditional discrimination experiments, the probability of a correct choice response is a function of the discriminability of responsereinforcer relations as well as bias for one choice response relative to the other. Bias is the change in response preference 
due to various experimental manipulations that is independent of sensitivity to the discriminative stimuli, referred to in signal detection theory as the signal (Nevin, 1981). The discriminability of a stimulus, or in signal-detection terminology, sensitivity or detectability, is influenced by the properties of that stimulus and the background (noise) in which it is presented. Bias is influenced by the probability of presentation of stimuli and by the relative probability of reinforcement for each choice irrespective of the signal (Lattal, 1979). A signal-detection analysis allows the individual effects of bias and detectability to be separated. It is thus possible to determine the degree to which the discriminability of responsereinforcer relations is controlling responding in a conditionaldiscrimination procedure in which choice responding is dependent upon which of two schedules produced a choice component.

Lattal (1979) and Killeen (1978) demonstrated that responsereinforcer relations serving as discriminative stimuli in conditional discriminations function much the same as any other exteroceptive stimulus. In Killeen's (1978) procedure, described above, the duration of reinforcers following a choice response corresponding to response-dependent and response-independent was varied from 1.8 to $3.8 \mathrm{~s}$. Bias for the choice with the greater reinforcer magnitude increased as the discrepancy between the two reinforcers increased. Lattal (1979) also demonstrated changes in 
bias as a function of the probability of the next matching-tosample (MTS) trial resulting from the completion of the DRO or the DRL (see above). Bias for the choice response corresponding to completion of the DRO increased as the probability of the next trial being assigned to the DRO increased. In both of these experiments, discriminability $\left(d^{\prime}\right.$ and $A^{\prime}$, respectively) remained relatively constant at high levels across all conditions, suggesting that changes in choice responding were a function not of decrements in discrimination but of changes in bias.

$$
\text { Alsop and Davison (1992) and Jones and Davison (1998) }
$$

conducted studies, described above, similar to those of Killeen (1978) and Lattal (1979) using the response-reinforcer relations generated by concurrent schedules as discriminative stimuli. As in other studies, bias was a function of the probability of a choice component being produced by the schedule associated with the brighter stimulus and by the probability of a correct red or green choice being reinforced. These data conform to the same pattern as those obtained with exteroceptive stimuli (except perhaps Jones and Davison, 1998, Conditions 7-14).

The experiments of Lattal (1975, 1979), Killeen (1978, 1981), Alsop and Davison (1992), and Jones and Davison (1998) taken together indicate that differences often attributed to failures or successes of response-reinforcer discriminability may be the result of bias. Discrimination of response-reinforcer 
relations is influenced by the probability of reinforcement for reporting that one of two schedules was effective. This has been demonstrated with response-dependent and response-independent reinforcement. However, due to the problems associated with Alsop and Davison's (1992) and Jones and Davison's (1998) procedures, it remains unclear whether or not changes in measures of discrimination of concurrent schedules are a function of bias or sensitivity 
Statement of the Problem

The discriminative properties of schedules of reinforcement have been investigated employing a conditional discrimination procedure using a number of schedules including DRO and DRL schedules (Lattal, 1975, 1979), response-dependent and responseindependent food delivery (Killeen, 1978, 1981), and concurrent VI schedules (Alsop and Davison, 1992; Jones and Davison, 1998). The aspects of these schedules and of the behavior they generate that serve a discriminative function remain unclear. Specifically, the extant research has not elucidated the role of temporal contiguity between a response and a reinforcer and the response-reinforcer dependency in such discriminations.

The aspects of schedules, which may serve a discriminative function, are many. The direct variables of schedules, such as two ratio sizes, may function as discriminative stimuli. Indirect effects such as the relative rate of reinforcement by two VI schedules, or the relation between response-rates and reinforcer delivery of two schedules also may serve a discriminative function. Whether direct or indirect variables are discriminated is determined by the experimenter and the way in which the contingencies are programmed. When indirect effects serve as discriminative stimuli the way in which they are discriminated is determined not by the researcher but by the nature of the relevant response-reinforcer relations generated. That is, the 
response-reinforcer relations to be discriminated are a function of the psychologically relevant indirect variables generated by schedules of reinforcement (i.e., how reinforcement has its effects on behavior).

It is possible that the response-reinforcer relations generated by concurrent schedules of reinforcement that can serve as discriminative stimuli can be measured only over extended periods of time (i.e., molar relations between responding and consequences). Killeen's (1978) findings suggest that this is not necessarily the case. Rather, the dimension of the responsereinforcer relations generated by time-based schedules that serves a discriminative function appears to be the time between a response and a reinforcer. He reported that those events that were temporally contiguous with responding were treated as if they were dependent. This finding indicates that it was not the rate of reinforcement in the absence and presence of responding over time that controlled choice responding but rather the context in which a single reinforcer was delivered.

The current experiments attempted to demonstrate that the discriminative properties of time-based schedules are the result of local response-reinforcer relations. Further, these studies assessed whether temporal contiguity between a response and an environmental event was sufficient for that event to be treated as if it had been caused by behavior. In the experiments by 
Lattal (1975, 1979, 1981) and Killeen (1978, 1981) two aspects of the response-reinforcer relation were manipulated simultaneously. The patterns of responding generated by the schedules employed resulted in reinforcer deliveries that were both contingent on a response and temporally contiguous with that response or reinforcer deliveries which were not contingent on a response and subsequently, were less or variably contiguous with a response. Only Warner (1990) arranged response-reinforcer relations that were similar with respect to temporal contiguity but differed in the response-reinforcer dependency. The failure of the relations arranged by Warner to control choice in a conditional discrimination suggests that the controlling variable in Lattal's and Killeen's studies was the difference in contiguity and not contingency. These findings also suggest that it was the local response-reinforcer relations that served a discriminative function and not those relations extended in time. 
Experiment 1

Experiment 1 assessed the discriminative properties of schedules in a procedure similar to that of Alsop and Davison (1992) and Jones and Davison (1998) except that a two-key concurrent schedule procedure was used. A two key procedure has the advantage of eliminating schedule-correlated stimuli. Variable-time choice components were introduced during the latter part of Experiment 1 to determine at what delays between a response and a choice component would the choice no longer control responding to the choices correlated with the VI schedules. A "neither" response was included during the last condition of Experiment 1 to determine at what delays between a VI response and a choice did pigeons report that the choice component was not a function of their behavior. These procedures allowed a replication of Alsop and Davison's (1992) and Jones and Davison's (1998) work with the subsequent introduction of response-independent events. They also allowed a replication of Killeen's (1978) procedure except that responding to a neither key was not explicitly trained and response-independent events were introduced after a baseline of response-dependent relations had been established.

Method

Subjects

Four adult White Carneau pigeons with a history of 
responding on various schedules of reinforcement served as subjects. Each pigeon was individually housed in a room separate from the experimental area, where it was given free access to grit and water. Each pigeon was maintained at $80 \%$ of its freefeeding weight with post-session supplemental feedings when necessary

Apparatus

An operant conditioning chamber with internal dimensions of 31 by 31 by $38 \mathrm{~cm}$ was enclosed in a sound-attenuating, ventilated enclosure. The work panel contained four 2.9-cm response keys. Two keys were mounted $5 \mathrm{~cm}$ above and below the center of the panel and two keys were mounted $6 \mathrm{~cm}$ to the left and right of the center of the panel (see Figure 1). Each key required a force of approximately $0.15 \mathrm{~N}$ to operate and could be transilluminated either red, green, or white. Primary reinforcers consisted of $4 \mathrm{~s}$ access to grain delivered from a Gerbrands model G5610 food hopper available through a 6 by $6-\mathrm{cm}$ aperture, the center of which was located $10 \mathrm{~cm}$ to the right of the center of the work panel and $10 \mathrm{~cm}$ from the floor of the chamber. During food presentations, the house light was extinguished. A ventilation fan and white noise generator masked extraneous noise. Contingencies were programmed, and data recorded, on an IBM-compatible computer operating with Med-pc() software. 

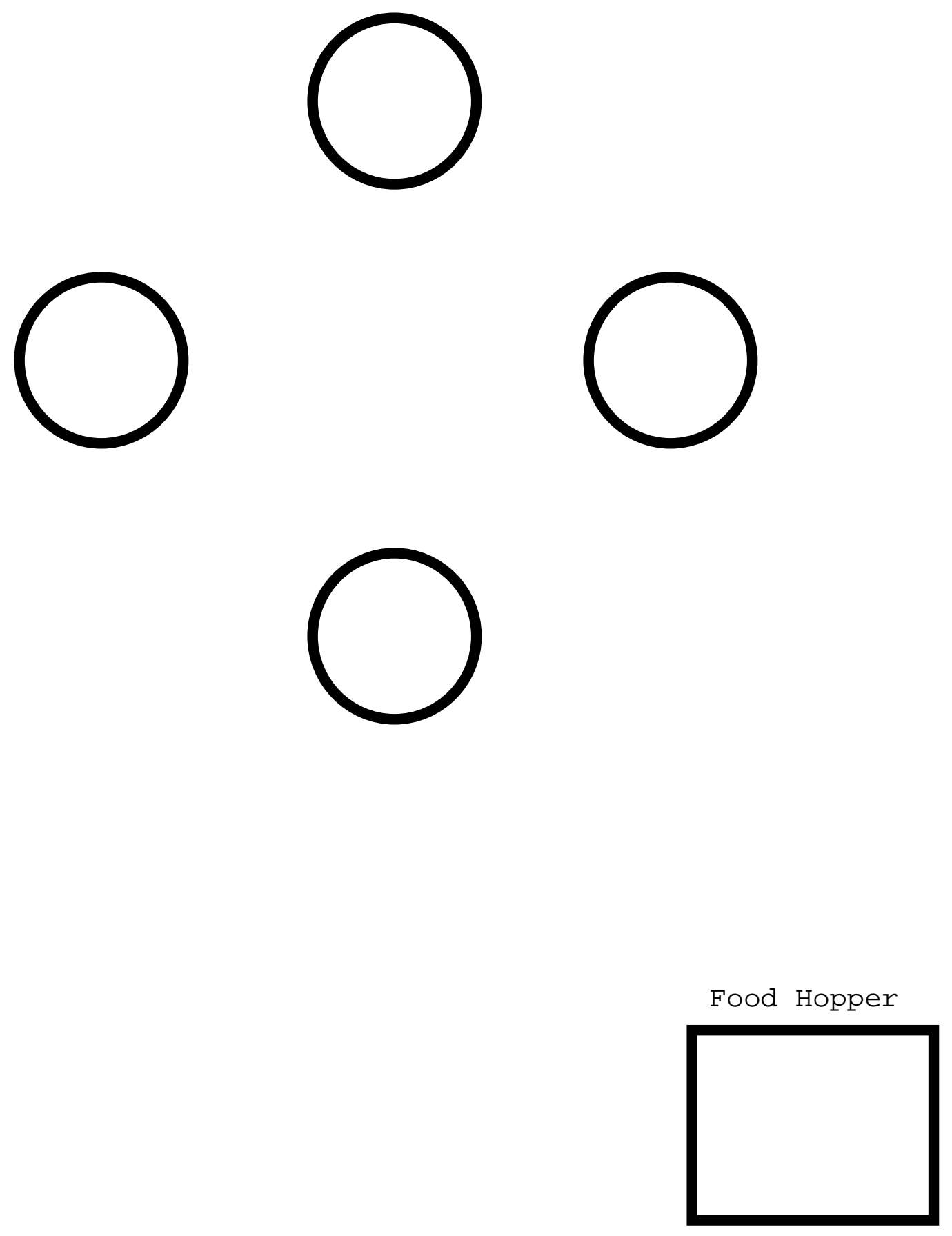

Figure 1. Schematic of the work panel configuration used in the experiments. The schematic is not to scale.

23 


\section{Procedure}

Because each pigeon had prior experience on various schedules of positive reinforcement, hopper training and shaping of key pecking were not necessary. Each pigeon initially was trained on two interdependent concurrent VI 15-s schedules of food delivery. The interdependent-concurrent VI schedules arranged for a reinforcer to become available on one of the two schedules, on average, once every 15 s (Stubbs \& Pliskoff, 1965). The next interval began only after the current reinforcer was collected. At the end of each interval, the schedule that resulted in the next reinforcer was chosen according to some probability depending on the concurrent schedules being used. Both side keys were illuminated white. Intervals were generated using Fleshler and Hoffman's (1962) constant probability progression. A DRO 3-s was programmed such that $3 \mathrm{~s}$ had to elapse from the last response until a response to the other key (the changed-to key) was eligible for reinforcement.

At the end of an interval, the schedule arranging the next reinforcer was selected randomly with a constant probability of 0.5 that the left VI schedule was the schedule in effect. The mean VI inter-reinforcer interval was increased by $15 \mathrm{~s}$ after 2-3 days at the previous value until the average interval duration was 60 s. This schedule is equivalent to a concurrent VI 120-s VI 120-s 
schedule. That is, a reinforcer became available every $60 \mathrm{~s}$ on average and over the course of multiple sessions, the number of reinforcers assigned to each VI schedule was approximately equal. When responding stabilized on the final concurrent schedules a conditional-discrimination procedure was implemented. A response after the current interval lapsed now produced a choice component during which both side keys were extinguished and the top and bottom key were illuminated green or red with a constant probability of 0.5 that the bottom key was illuminated red. A response to the red key was followed by $4-s$ access to grain if the left VI schedule produced the choice trial. A response to the green key was followed by $4-s$ access to grain if the right VI schedule produced the choice trial. A choice response was defined operationally as 3 responses to either key. This definition was employed successfully in a pilot study to prevent carryover responses from being counted as choice responses and remained in effect for the current studies. Incorrect choices initiated a correction procedure. The side key correlated with the VI schedule that produced the choice trial was reilluminated. Five responses to that key resulted in another choice trial, with the location of the key illuminated red randomly selected. Accurate correction-trial choices were reinforced and this procedure continued until a correct response occurred.

The reinforced response after each type of sample was 
reversed across conditions. That is, in Condition 1, a response to the green choice key on a choice component produced by the right VI schedule was reinforced. In Condition 2, a response to the red choice key was reinforced during a right VI initiated choice component. Each condition continued until choice accuracy remained at or above 90\% for at least 6 days. Table 1 provides the conditions for each pigeon. The term "lean" in Table 1 at Condition 5 indicates that the percentage of reinforced correct choices was reduced to 50\% after the third reversal. Added Variable-Time Food Presentations. Concurrent VI 160-s VI 160-s and variable-time (VT) 240-s schedules produced choice components during probe sessions. This resulted in 10 responseindependent choice component presentations per 40 trial session. Variable-time produced choice components and 1/3 of VI-produced choice components were extinction trials. That is, correct choices on $1 / 3$ of VI produced choice components were followed immediately by the next trial. All of VT choice components were followed immediately by the next trial, thus the correction procedure was not in effect following VT choice components. This resulted in 50\% of all correct choice responses being reinforced as in the previous condition. On those choice components produced by the VT schedule, the side keys were randomly illuminated red or green. A response to either of the keys immediately initiated the next sample component. Sessions 
Table 1. Sequence of conditions for pigeons for Experiment 1.

Red-Right / Green-Left

$100 \%$ of correct choices reinforced

Green-Right / Red-Left

$100 \%$ of correct choices reinforced

Red-Right / Green-Left

$100 \%$ of correct choices reinforced

$$
\begin{gathered}
\text { Red-Right / Green-Left } \\
\text { Lean }
\end{gathered}
$$

$50 \%$ of correct choices reinforced

Red-Right / Green-Left VT choices introduced

67\% of correct choices reinforced

$.5 / .5$ signal detection condition

Red-Right / Green-Left VT choices

$.7 / .3$ signal detection condition

Red-Right / Green-Left VT choices $.3 / .7$ signal detection condition

Red-Right / Green-Left VT choices 67\% of correct choices reinforced Bottom choice required on all VT trials 
ended after 40 choice components were presented (excluding correction trials) and were conducted 7 days a week. Conditions lasted at least 15 sessions and until 90\% percent of choices were correct for 6 consecutive days.

Signal Detection Analysis. The probability that a correct green or red response was reinforced was manipulated upon completion of the VT-probe sessions. The VT-probe sessions served as the baseline for the signal detection conditions. In the first condition of the signal detection procedure the probability that a correct red choice response was followed by food remained 0.5 and the probability that a correct green choice response was followed by food was 0.5 . In the second condition, correct green choices were reinforced according to a 0.7 probability and correct red choices were reinforced according to a 0.3 probability. In the third condition correct red choices were reinforced according to a 0.7 probability and correct green choices were reinforced according to a 0.3 probability (see Table 1) Variable-time produced choice components were extinction trials. All VT-choice responses were followed immediately by the extinguishing of the red and green light and the illumination of the two side (VI) keys. Each condition was in effect for 15 days. Sessions occurred 7 days per week.

Variable-time Detection. Upon completion of the signaldetection conditions, the ratio of correct choices followed by 
food was returned to $1: 1$ (i.e., a 0.5 probability of reinforcement for each correct choice). Choice components produced by the VT schedule were not followed by food, but a response to the bottom choice key, irrespective of color, was required for the choice keys to be extinguished and for the VI keys to be illuminated. Responses to the top choice key were recorded but had no programmed consequence. This allowed an assessment of the discriminability of response-independent choice component presentations.

Results

Variable-interval response rates across the first 5 conditions are shown in Figure 2. Response rates were calculated by dividing the number of responses to each key by the total session time minus the time spent in choice components and while food was being presented. Response bias for either the left or right VI schedule developed for all pigeons except 8950. Response rates for Pigeons 5358 and 905 were higher on the right VI key and rates for Pigeon 8535 were generally higher on the left VI key. Rates of reinforcement were controlled by programming interdependent interval schedules. The overall rate of reinforcement did not vary significantly between pigeons as judged by the amount of time required to attain 40 reinforcers. Acquisition of the conditional discrimination occurred in 20 days or less for 3 of the 4 pigeons. Choice accuracy was 
Figure 2. Responses per minute to the two VI keys for each pigeon during each condition of the first part of Experiment 1. Rates were calculated by dividing the number of responses to each key by total session time excluding time spent in choice components and reinforcement time. The labels ABLQ ARev 1@ and ARev 2" correspond the first four conditions. Alean@indicates the point at which the percentage of reinforced choice components was reduced to 50\%. AVT@indicates the point at which VTproduced choice components were introduced. Note that the scale on the $\mathrm{x}$-axis is different for each pigeon. 

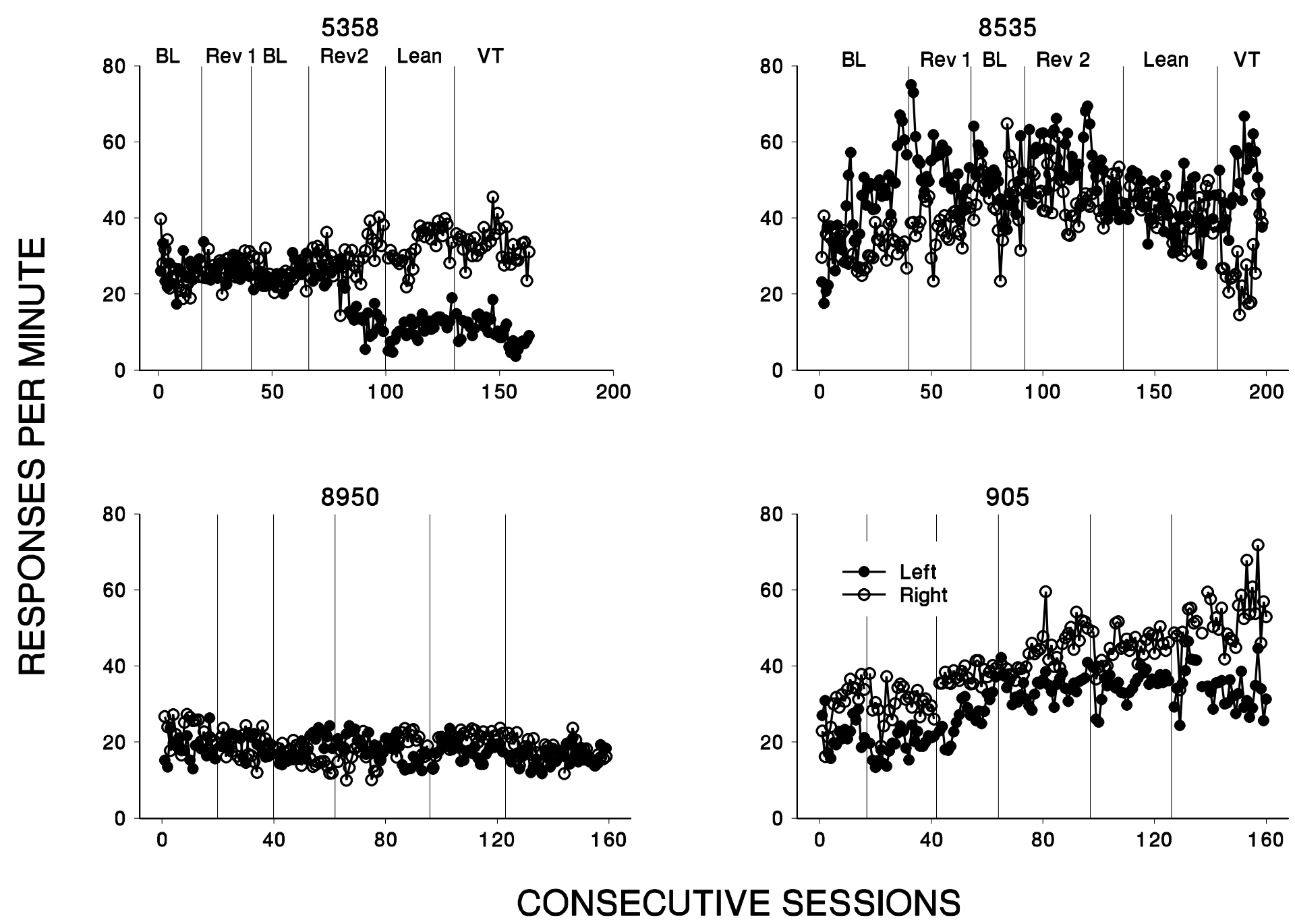
calculated by dividing the number of correct choice responses, excluding correction trial responses, by 40 , which was the total number of choices excluding correct trials. Figure 3 shows that choice accuracy exceeded that predicted by chance (50\%) after no more than 8 sessions and as few as 2 sessions. The percentage of correct responses met or exceeded 90\% for the last 6 days of each condition. Reversing the correct choice response for trials initiated by the left or right VI schedule reduced accuracy well below chance levels initially followed by a rapid increase in correct choice responding. The number of sessions required for choice accuracy to reach 90\% following a reversal in correct choice responses varied, but typically was between 20 and 30 . Responding in choice trials was not related to the aforementioned side biases in VI responding. Figure 4 shows the number of incorrect choices, including correction-trial choices by session, for choice trials resulting from the left and right VI schedules. The type of error made did not vary systematically across sessions, indicating a lack of bias for one choice response over the other, nor were errors related to any existing VI side biases. The number of errors made increased sharply when correct choice responses were reversed and declined quickly to zero or near-zero over successive sessions. The introduction of VT choice trials had no systematic effect on choice responding. Choice responding remained accurate 
Figure 3. The percentage of correct choice responses by each pigeon during choice components excluding correction trials for the first part of Experiment 1. The labels ABLQ ARev 1@ and ARev 2" correspond the first four conditions. Alean@indicates the point at which the percentage of reinforced choice components was reduced to 50\%. ATT@indicates the point at which VTproduced choice components were introduced. 


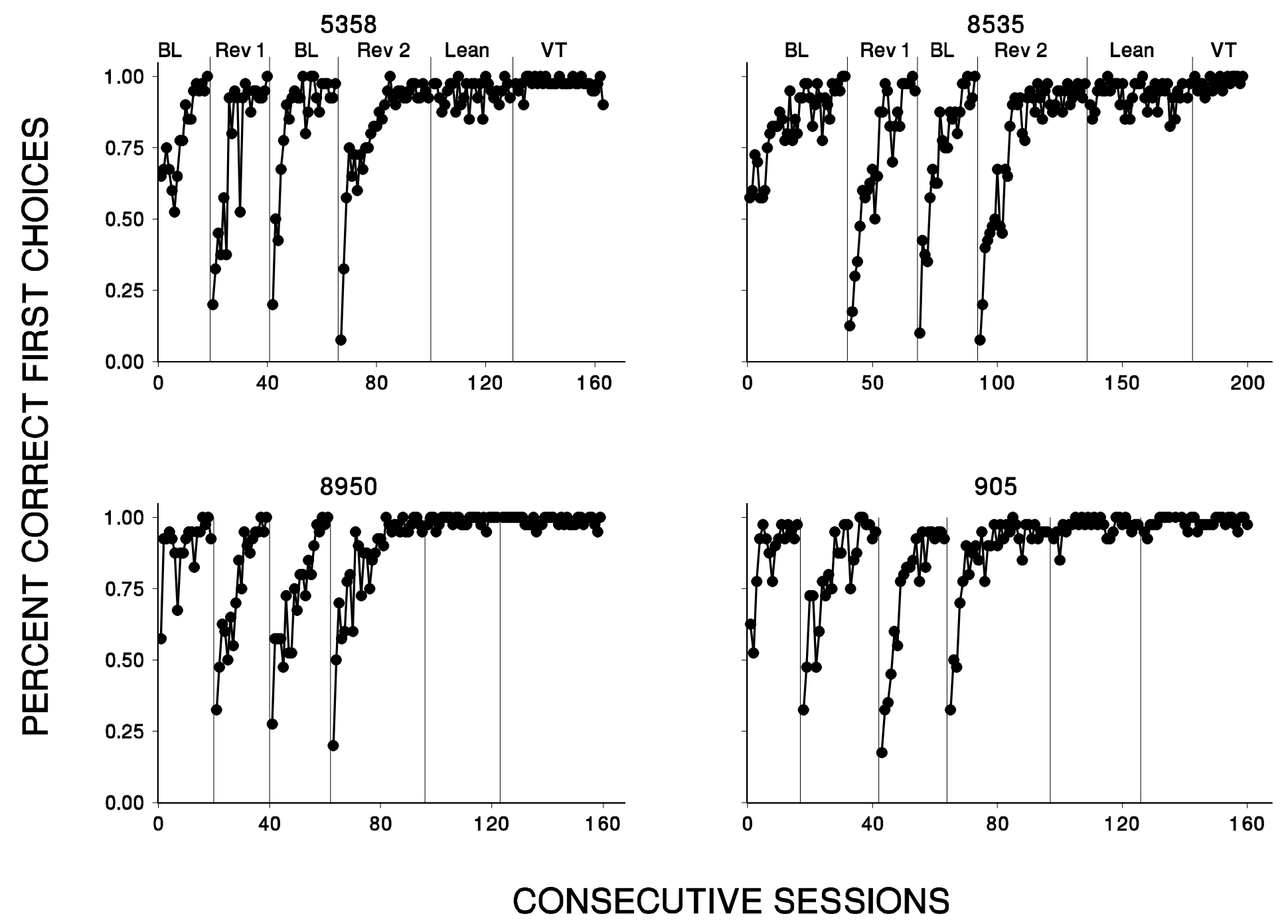

Elgure 3 . 
Figure 4. The total number of incorrect choices per session for each pigeon during the first part of Experiment 1. The two types of errors were those made on choice components produced by a left VI peck and those produced by a right VI peck. The labels ABL@ ARev 1@ and ARev 2" correspond the first four conditions. Alean@ indicates the point at which the percentage of reinforced choice components was reduced to 50\%. ArT@indicates the point at which VT-produced choice components were introduced. Note that the scale on the $x$-axis is different for each pigeon. 


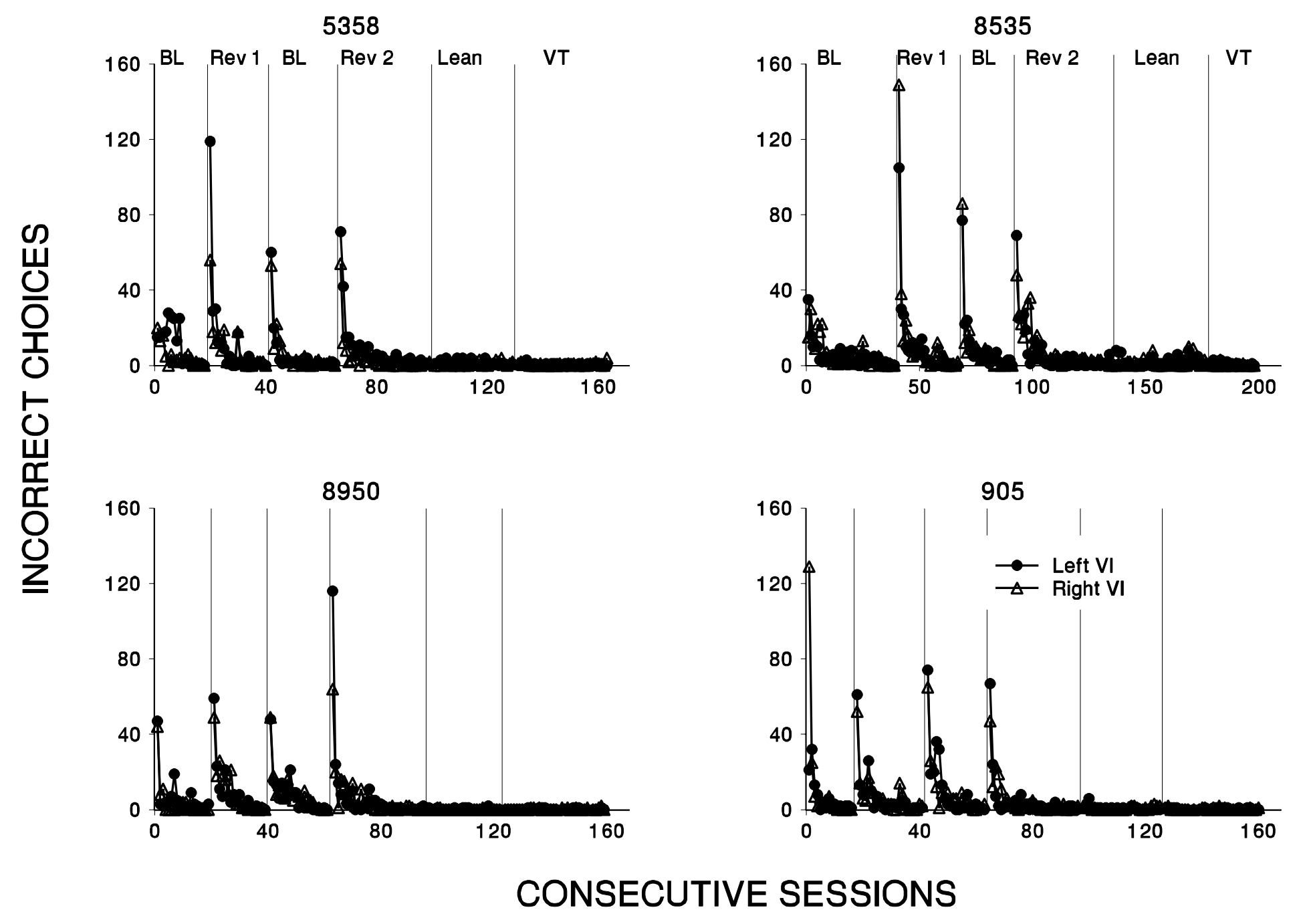


and the type and frequency of errors was unaffected. Variableinterval responding did not vary as a function of the introduction of VT-produced choice trials for 3 of 4 Pigeons. The response rates of Pigeon 8535 show a clear but transient preference for the left VI key when the VT choices were added.

The second part of Experiment 1 examined the conditions that result in less control of choice responding by the trained discrimination. The first signal-detection condition was identical to the VT condition in the first part of Experiment 1. In this condition there was a strong preference for one of the two VI schedules for all 4 pigeons. Figure 5 shows that the response rates of two pigeons were higher on the right VI key and rates for the other two pigeons were higher on the left VI key. Rates were calculated by dividing the number of responses on each key by total session time minus time spent in choice components and the time that food was being presented. When the ratio of reinforcers was changed so that $70 \%$ of correct green choices (i.e., those choices produced by the left VI schedule) were reinforced and 30\% of correct red choices were reinforced, the side bias for Pigeons 5358 and 8950 became less pronounced and for Pigeon 8535 the difference in response rates became more pronounced. In each of these three cases, response rates on the left VI increased. Response rates on the right VI key increased for the same three pigeons when the ratio of reinforced choices 
Figure 5. Responses per minute to the VI keys across conditions for each pigeon during the second part of Experiment 1 . Rates were calculated by dividing the number of responses to each key by total session time excluding time spent in choice components and reinforcement time. The ratios indicate the ratio of reinforced correct choices on left-VI produced choice components to reinforced correct choices on right-VI produced choice components. ABottom@indicates the point at which a response to the bottom choice key was required to terminate VT-produced choice components. Note that the scale on the x-axis is different for each pigeon. 


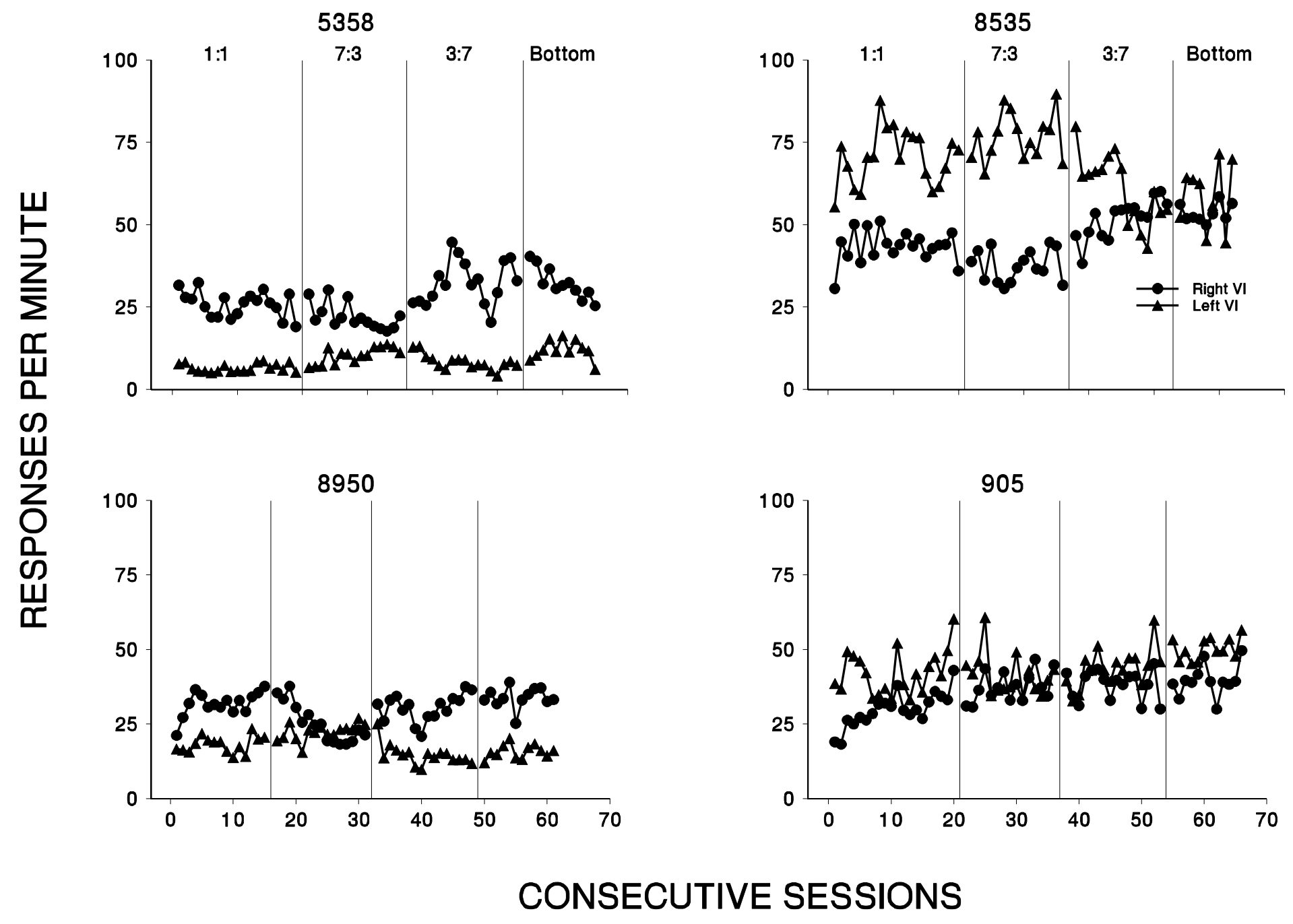


was reversed so that $70 \%$ of correct red choices were reinforced and $30 \%$ of correct green choices were reinforced. Response rates after the final reversal, in which rates of reinforcement on the choice keys were made equal again, were approximately equal to those prior to the manipulation of reinforcement rates. This suggests that changes in VI response rates were a function of changes in the probability of reinforcement for correct choice responses.

Figure 6 shows accuracy for each pigeon across the final four conditions. Choice accuracy was unaffected by manipulations of the probability of a response being reinforced. Accuracy was calculated by dividing the number of correct choices on VIproduced trials, excluding correction trials, by 30 . The number of incorrect responses in a session did not exceed 2 except during the final two conditions for Pigeon 8535. These data indicate that choice responding on VI produced choice components was independent of the relative probability of a response resulting in reinforcement.

Responding during VT-produced choice trials was a function of the time between a VI response and the onset of a choice trial. Figure 7 shows the number of choice responses on VT-produced trials that correspond to the last VI key peck (i.e., the number of red key pecks on VT choice trials preceded immediately by a right VI response and the number of green 
Figure 6. The percentage of correct choice responses on choice components excluding correction and VT choice components for each pigeon during the second part of Experiment 1 . The ratios indicate the ratio of reinforced correct choices on left-VI produced choice components to reinforced correct choices on right-VI produced choice components. ABottom@indicates the point at which a response to the bottom choice key was required. 

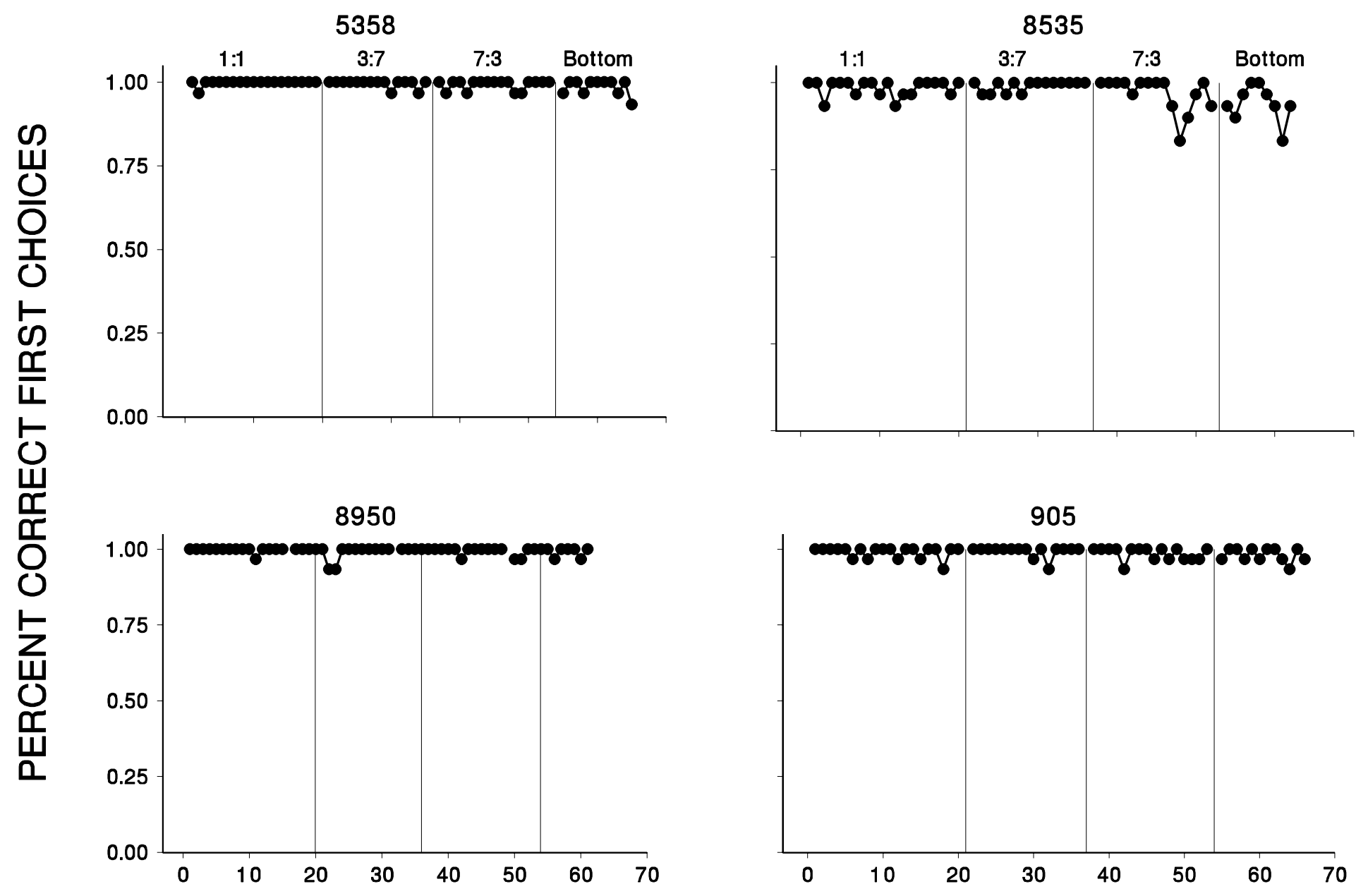

CONSECUTIVE SESSIONS 
Figure 7. The percentage of choice responses that corresponded to the last VI peck on VT-produced choice components for each pigeon as a function of the time between the last VI peck and the choice component onset. The different lines represent the different signal-detection conditions as identified in the legend in the upper right corner of the figure. 

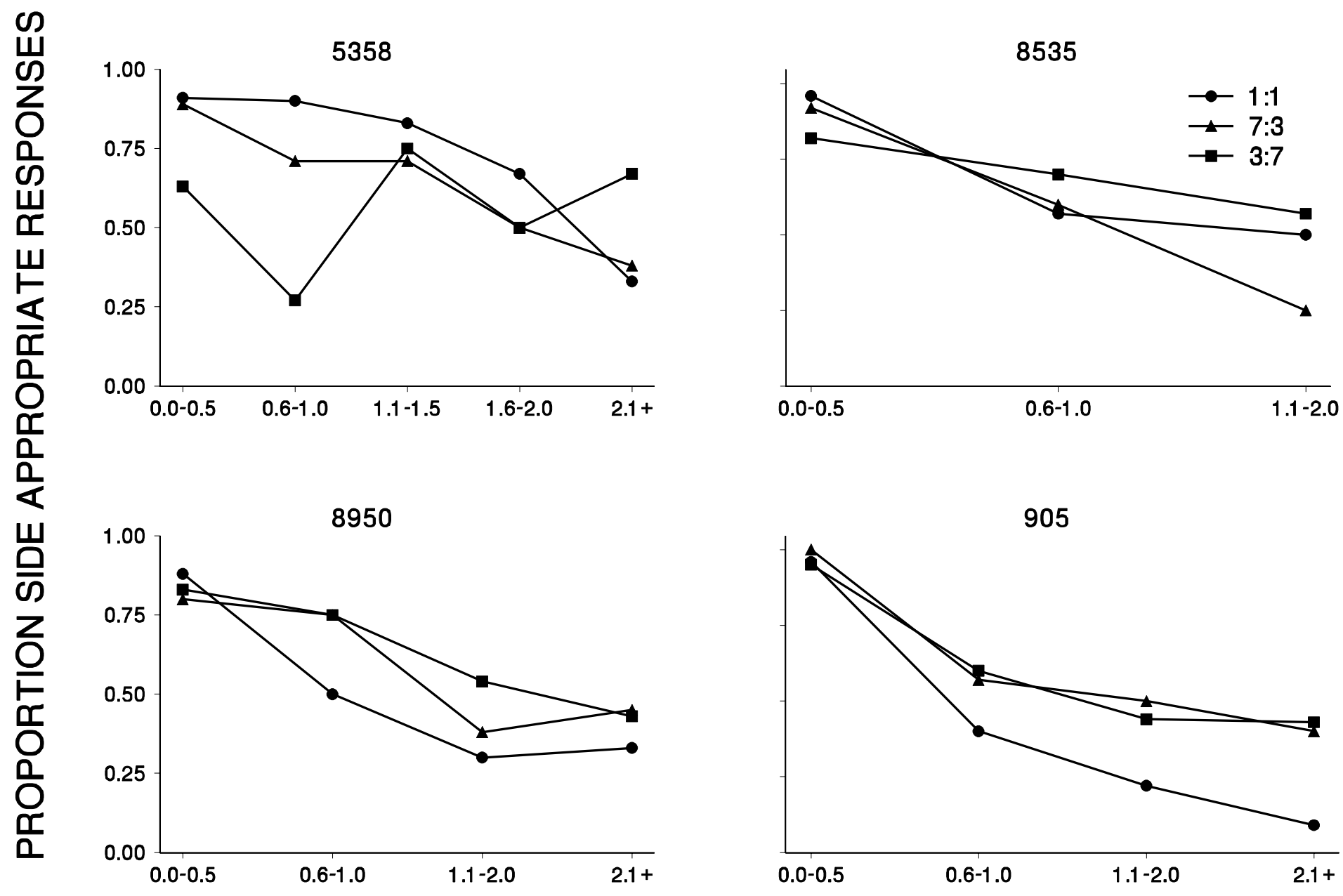

DELAY (s) 
responses on trials preceded by a left VI response). Each obtained delay curve is comprised of the data from the last 6 sessions of each signal detection condition. At delays of 0 to $0.5 \mathrm{~s}$, choice responding typically corresponded to the last VI peck, Pigeon 5358 during the 3:7 condition being the exception. As delays from a VI response to a choice trial lengthened, choice responding was independent of the previous VI response with a graded decrement in accuracy for 11 of 12 conditions. Occasionally, the proportion of side-appropriate choice responses dropped below 0.5 , the predicted value if choice responding were random. This was probably the result of an insufficient sample size rather than systematic variation in responding.

In the final condition of Experiment 1, a response was required to the bottom choice key on VT-produced choice trials, irrespective of key color, to advance to the next VI or VT sample component. Figure 8 shows the proportion of bottom responses to bottom and top responses on VT-produced trials for each pigeon as a function of the delay from a VI response to the choice component. At very brief delays (0-0.2 s) choice responding was distributed evenly among the two alternatives. Figure 7 shows that responding was under the control of the previous VI response. Figure 8 indicates that as delays increased, a bottom response became more probable and was therefore controlled by the response-independent choice contingency. It is clear that delays 
Figure 8. The percentage of choice responses during VT-produced choice components made on the bottom key irrespective of color during the final six sessions of Experiment 1 for each pigeon. Percentages are plotted as a function of the time between the last VI peck and the onset of the VT choice. 

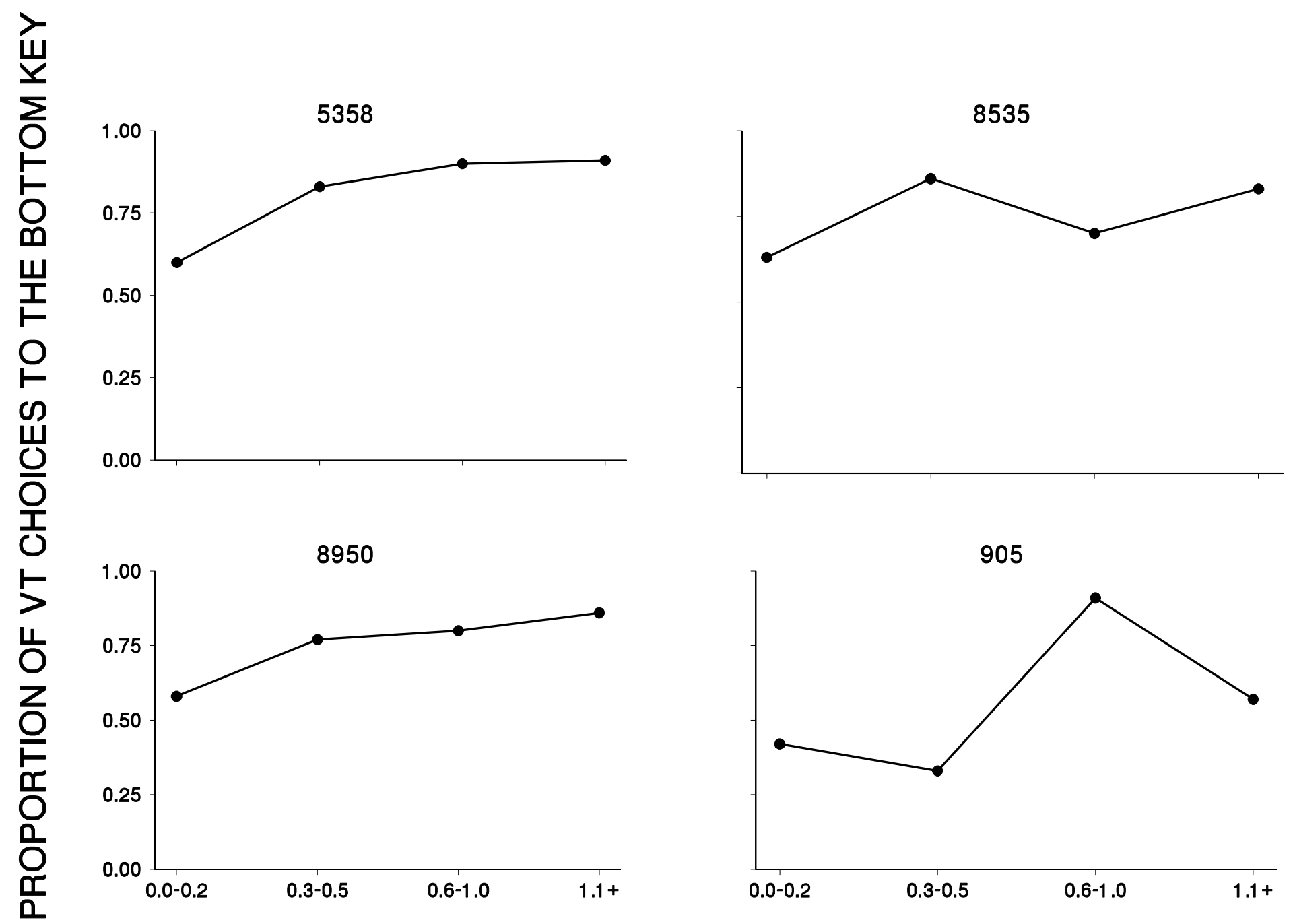

DELAY (s) 
of greater than $0.2 \mathrm{~s}$ were discriminable with greater control of responding as delays increased for 3 of the 4 pigeons.

\section{Discussion}

The data from the first 5 conditions of Experiment 1 indicate that the discrimination was learned with relatively few errors. Despite the side bias, which was present for 3 of 4 pigeons, choice responding was a function of the VI response that produced the choice trial. The number and type of errors that occurred indicate and absence of color bias. The introduction of VT-produced choice components in Condition 5 had no effect on choice responding on VI-produced choice trials nor did VI response rates change.

Changing the probability of a correct choice response resulting in reinforcement in Conditions 7 and 8 (the signal detection conditions) had no effect on choice responding. Alsop and Davison (1992) and Jones and Davison (1998) found that changing the probability of reinforcement following either choice response increased bias for that response. This results in an increase in the number of errors made. Changing the probability of reinforcement for one choice relative to the other choice being reinforced did not increase bias for the choice correlated with the higher probability of reinforcement in the current experiment, as the accuracy data in Figure 6 show. Altering the probability did not affect choice accuracy. The lack of bias in 
the current experiment was probably a function of the ease of the discrimination and the probability of reinforcement for a correct choice response relative to that for an incorrect response. Regardless of the ratio of reinforcement for correct red choice responses relative to correct green choices, the probability of reinforcement for a correct response was always greater than that for an incorrect response. This was true also for the studies of Jones and Davison (1998), Alsop and Davison (1992), Lattal (1979), and Killeen (1978). Bias for one choice relative to the other should occur only when there is some uncertainty about the stimulus presented (i.e., forgetting). The lack of bias in the current procedure may have been the result of the lack of baseline errors. That is, the ease of the discrimination may have blocked the biasing effects of altering the distribution of reinforced choice responses.

The absence of response bias for one choice over the other also may have been a function of a second, accidental discrimination. Choice responding during VT-produced choice components was never reinforced. Choice responding during the conditions that manipulated the probability of reinforcement seemingly was not controlled by the programmed reinforcement rate when delays between a VI response and a VT choice component were long. This may have been a function of the last response losing discriminative control with long delays, which should have 
resulted in a bias for one choice response over the other with differences in the relative rate of reinforcement for each choice. The absence of any response bias on the probe trials indicated that response-independent choices were discriminated from response-dependent choices. Choice responding during response-independent choices was never reinforced, therefore responding on VT-produced choices should be random since both responses resulted in the same outcome. This would only hold if response-independently produced choices were discriminable from VI-produced choices. The final condition tested whether this discrimination had been accidentally trained by starting the next trial after a VT choice only after a bottom choice response was made. The increase in bottom choices as obtained delays increased indicates that response-independent choice components were more discriminable as delays between a VI response and a VT choice increased.

The finding that VI response rates varied as a function of changes in the probability of a choice response was unexpected. Jones and Davison (1998) reported no change in concurrent schedule performance when the ratio of reinforced choice responses was varied. The effect of a similar manipulation in the current experiment was to increase response rates on the VI schedule correlated with the choice that had the higher relative probability of reinforcement. There was a corresponding decrease 
in response rates on the VI schedule associated with the choice with a lower relative probability of being reinforced. This relation held for 3 of 4 pigeons. There were no obvious procedural differences between the two experiments that would account for the difference. 
Experiment 2

In the first experiment, the effects of response-independent events on a baseline of response-dependent events were examined. The final condition of Experiment 1 indicated that responseindependent events controlled responding to a third "neither" response and that this control was a function of the delay between a response and a choice component. Experiment 2 was conducted to determine the effect of response-independent events with different delays from the last response when pigeons were given a history with a response-independent choice. The effects of a range of disruptions in the temporal contiguity between a response and reinforcer were investigated. Employing a DRO schedule of reinforcement controlled for the range of obtained delays and thereby allowed what was previously an indirect variable in Experiment 1 to be controlled as a direct one. Method

Subjects

Four adult white Carneau pigeons with a prior history responding on various schedules of reinforcement served as subjects. Each pigeon was individually housed in a room separate from the experimental area, where they were given free access to grit and water. Each was maintained at 80 to $85 \%$ of their freefeeding weights with post-session supplemental feedings when necessary 


\section{Apparatus}

The operant conditioning chamber used in the first experiment was used also in Experiment 2. Except for the following, other details of the apparatus were as in the first experiment. Primary reinforcers consisted of $3 \mathrm{~s}$ of access to mixed grain. During food presentations, the house light and key lights were extinguished.

\section{Procedure}

Because each pigeon had prior key-pecking experience, hopper training and shaping of key pecking was not necessary. Each pigeon first was trained to respond to the two side keys and the top center key when they were lit either red, green, or amber. Such responding was reinforced according to a VI 15-s schedule. One of the three keys was illuminated one of the three colors at the start of each session. After a reinforcer was delivered one of the three keys was randomly illuminated one of the three colors. This continued until each key had been illuminated each color at least three times at which point the session ended. When responding occurred reliably to all three keys lit all three colors, discrimination training began.

Conditional Discrimination. Discrimination training began with the houselight on and the two side keys illuminated white. Choice components were produced according to a concurrent (VI 30- 
s) (VI 30-s) (tandem VT 30-s DRO 2-s) schedule of reinforcement. A 3-s COD was programmed such that the next response was not eligible for reinforcement until at least $3 \mathrm{~s}$ had elapsed since a response on the other key. Each white side key corresponded to one of the VI schedules (i.e., left VI and right VI). Interdependent concurrent schedules (Stubbs \& Pliskoff, 1969) were programmed as in the first experiment to ensure equal exposure to each schedule and subsequently each type of choice component. The tandem VT 30-s DRO 2-s schedule required no responding to either of the side VI keys for 2 s after an interval averaging $30 \mathrm{~s}$. The probability of a choice component being produced by meeting the requirements of one of the schedules was held constant at 0.33. Thus, over the course of a session an equal number of choice components were produced by meeting the requirements of each of the three schedules.

Choice components resulted in the two side keys and the top key being illuminated either red, green, or amber. Each key had an equal probability of being illuminated each color over the course of a session. Choice responding was reinforced dependent upon which of the three concurrent schedules had produced the choice component. If the left VI schedule arranged the choice component then a green choice response was reinforced. If the right VI schedule arranged the choice component then a red choice response was reinforced. If the tandem VT 30-s DRO 2-s schedules 
arranged the choice component then an amber choice response was reinforced. A choice response was defined as 3 pecks to any of the choice keys. Correct choice responses were followed by the extinguishing of the keys and houselight and food delivery. Incorrect choice responses resulted in a 3-s blackout followed by a correction trial. Correction trials were identical to noncorrection trials except that on correction trials the schedule that arranged the next choice component was always the same as on the previous trial. Sessions lasted until 30 reinforcers were obtained and were conducted 7 days a week. Sessions were conducted until the percentage of correct choice responses stabilized, as judged by visual inspection of these data. Probe Tests. Probe test sessions were introduced when the number of errors per session stabilized for the previous condition. Two probe test sessions were conducted separated by one of the conditional-discrimination sessions. Probe sessions were identical to the conditional discrimination sessions except that the tandem VT 30-s DRO 2-s schedules were changed to tandem VI 30-s DRO $x-s$ schedules. The DRO values were $0.25,0.50,0.75$, $1.00,1.50,2.00,2.50,3.00,3.50$, and $4.00 \mathrm{~s}$. All tandem VT DRO choice components resulted in reinforcement after an amber choice response. The correction procedure remained in effect.

Results

Responding on the two VI keys occurred at low rates for each 
pigeon and ranged from approximately 10 to 25 responses per minute. Figure 9 show the number of responses per minute on each VI key as well as an index of pausing for each session. Rates were calculated by dividing the number of responses or pauses by the total session time. The rate of pausing was higher for each pigeon during the first 17 sessions relative to subsequent sessions. This is the result of only counting the first $2-s$ pause after a response from the 18th session to the end of the experiment. Prior to this, each 2-s period that elapsed without a response was counted as a separate pause. This inflated the rate of pausing by counting long inter-response times as multiple pauses. During the first 17 sessions, a 5-s pause was counted as 2 pauses and ignored the last 1 s of not responding despite the fact that it was that last second that was part of the "reinforced" pause. The magnitude of the response was ignored by only counting a pause once. This seems reasonable because the magnitude was not a relevant dimension of the response. Response rates on each VI key were approximately equal for Pigeons 4836 and 4845. A right side bias developed for 4873 and a left side bias developed for 4898 .

The probability of a correct choice on a three choice matchingto-sample procedure, if responding is not a function of the sample stimuli, should be 0.33. Choice accuracy in the current experiment was approximately 0.33 for the first $2-4$ 
Figure 9. Responses per minute to the VI keys and pauses per minute for each pigeon during Experiment 2. Rates were calculated by dividing the total number of responses by session time excluding time spent in choice components and reinforcer presentations. At session 18 total pauses were limited to the first 2-s pause after a response. 


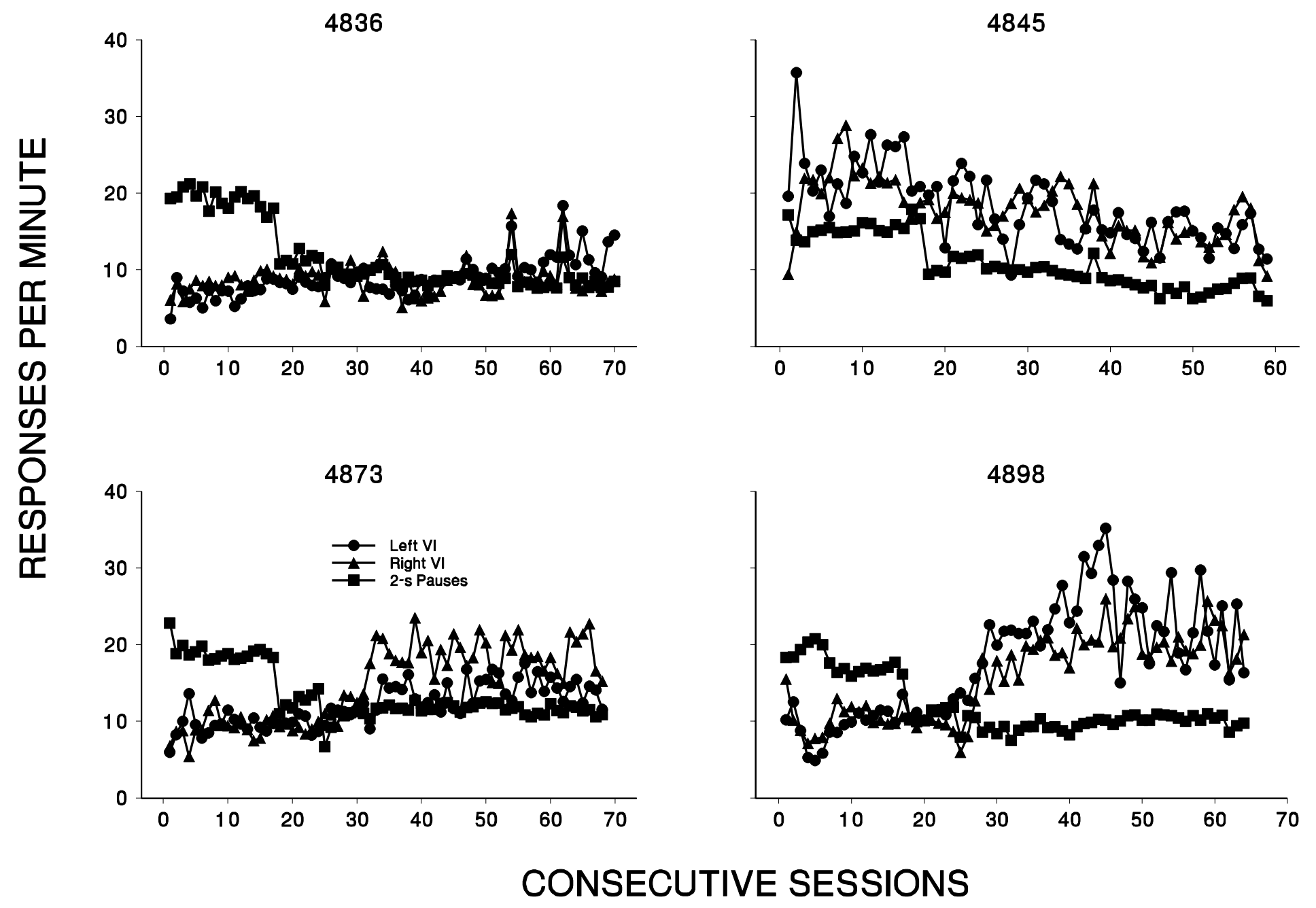


sessions for all pigeons. Figure 10 shows the percentage of correct choices for each pigeon during each session of the experiment. Probe sessions are indicated by the vertical arrows. Accuracy was calculated by dividing the total number of choice trials, including the correction trials, by the number of correct choices. Unlike Experiment 1, correction trials were included in the current analysis because during this second experiment there was nothing to distinguish correction from non-correction trials. Accuracy increased throughout experiment for all pigeons. The percentage of correct choices was as high as 92\%, but typically fluctuated between 70 and $80 \%$. The VI side bias which developed with Pigeons 4873 and 4898 did not systematically affect choice responding accuracy. For Pigeon 4873, errors were more likely during choice trials arranged by the tandem VT 30-s DRO 2-s schedules. Figure 11 shows the frequency of all three error types for each pigeon across sessions. Each point corresponds to the number of times each error occurred during the session. There was a rapid decrease in the total number of errors during the first 10 to 20 sessions. The total number of errors per session decreased to approximately 10 by session 50 or 60 . Pigeon 4873 was more likely to report that a reinforcer was arranged by one of the VI schedules than the DRO. There was a weak bias for reporting the left VI over the right VI as reflected by the minimal number of errors on 
Figure 10. The percentage of correct choice responses for all choice components with each pigeon during Experiment 2. The arrows indicate the DRO-probe sessions. Note that the scale on the y-axis is different for each pigeon. 


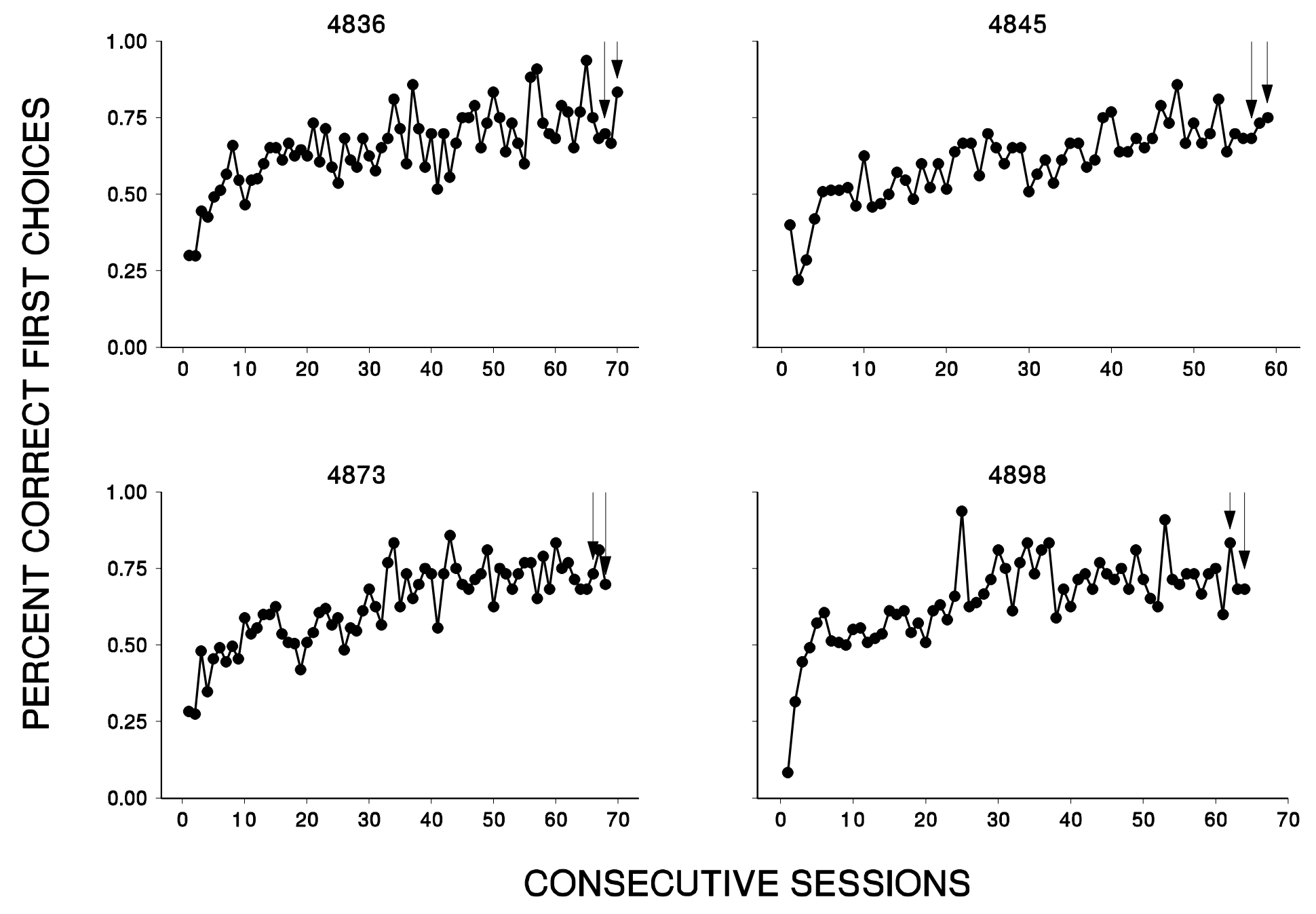


Figure 11. The total number of incorrect choices per session for each pigeon during Experiment 2. The three error types were those made on left-VI, right-VI, and DRO-produced choice components. Note that the scale on the y-axis is different for each pigeon. 

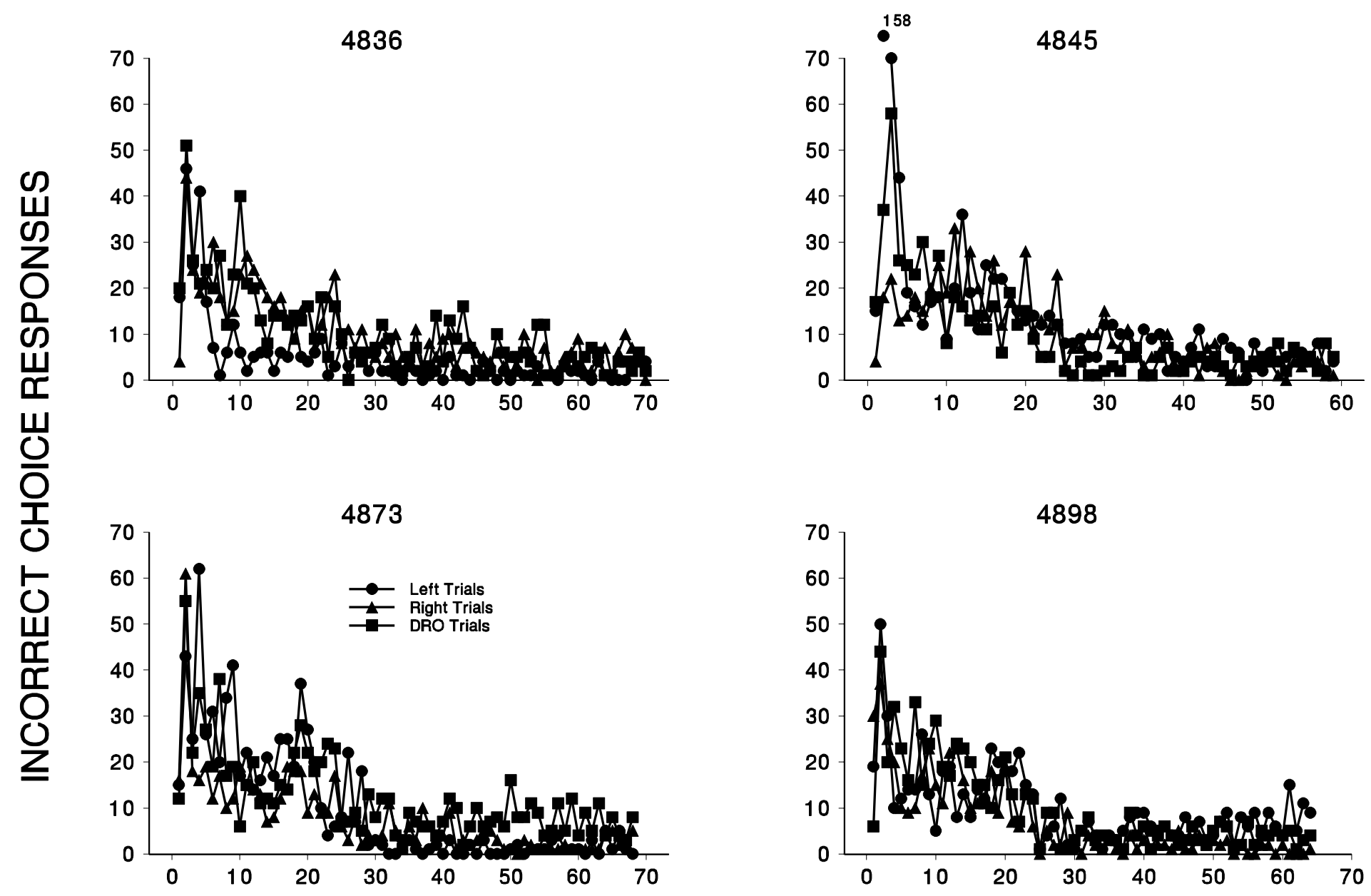

CONSECUTIVE SESSIONS 
left-VI produced trials. No other pigeon appeared to exhibit any systematic bias as the number of each error type varied from session to session.

Responding on DRO-produced choice components during DRO probes was characterized by high accuracy at shorter delays and decrements in accuracy as delays increased. Figure 12 shows the percentage of correct choices during DRO-produced choice components as a function DRO duration. Each point represents the percentage of correct choices for a range of DRO values. This was done to increase sample size and because separating each DRO value did not significantly alter the appearance of the figures. Percentages are combined over both probe sessions as there was no systematic variation from the first probe session to the second. Three of the pigeons, the exception being Pigeon 4836, had the lowest accuracy measures when DRO values were longest. Figure 13 depicts the average performance of all 4 pigeons across each individual DRO value. All probe trials from each pigeon were combined to produce the figure. The shape of the function is similar in to that in the individual figures for 3 of 4 pigeons, Pigeon 4836 being the exception. The increase in accuracy at the 4-s DRO was due primarily to Pigeon 4836. The probe sessions did not alter overall accuracy, response rates, or the distribution of errors. 
Figure 12. The percentage of correct choices made on DROproduced choice components averaged across the two DRO-probe sessions. 


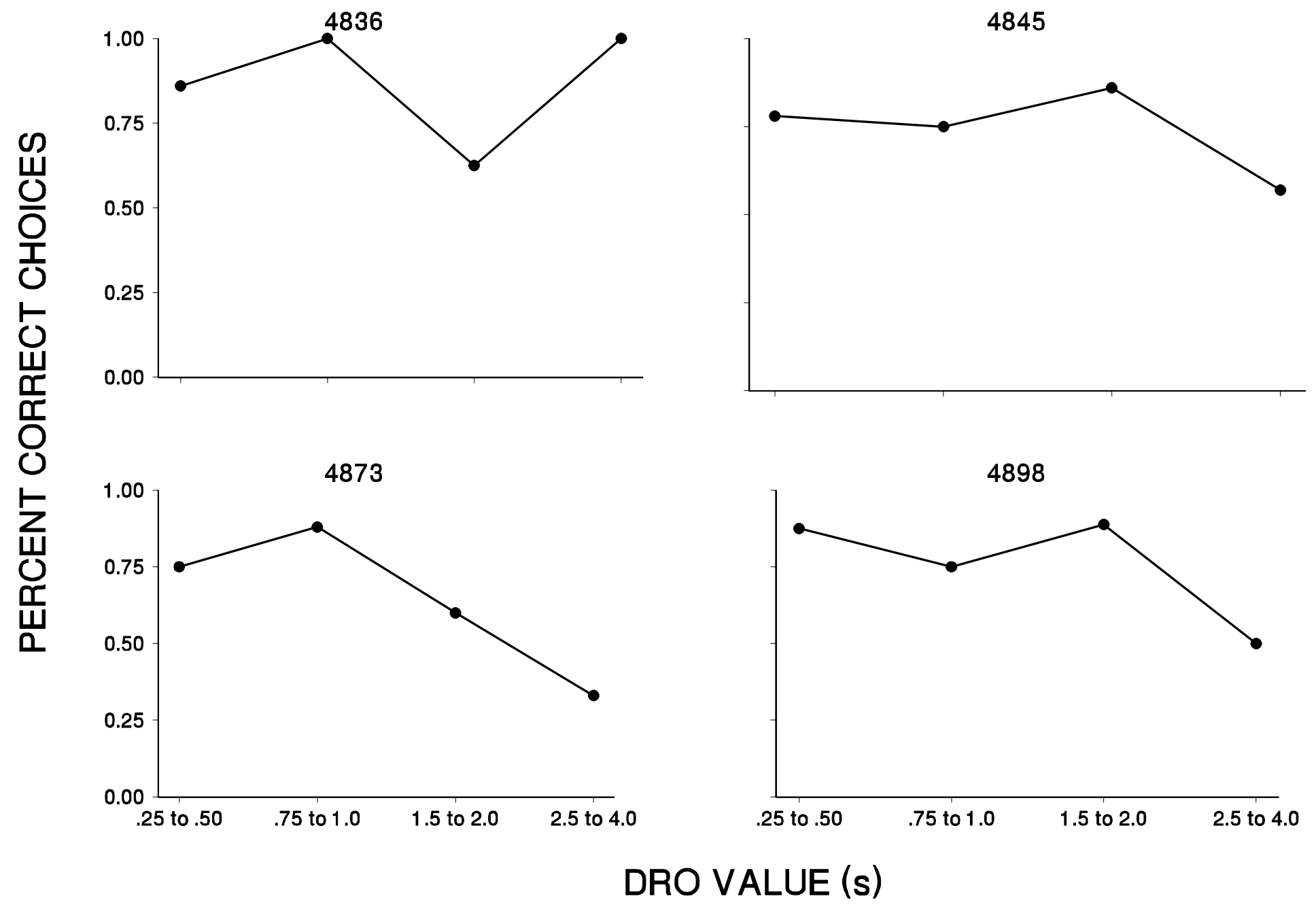


Figure 13. The percentage of correct choice responses averaged across pigeons during the two DRO-probe sessions. Percent correct is plotted as a function of the DRO value. 


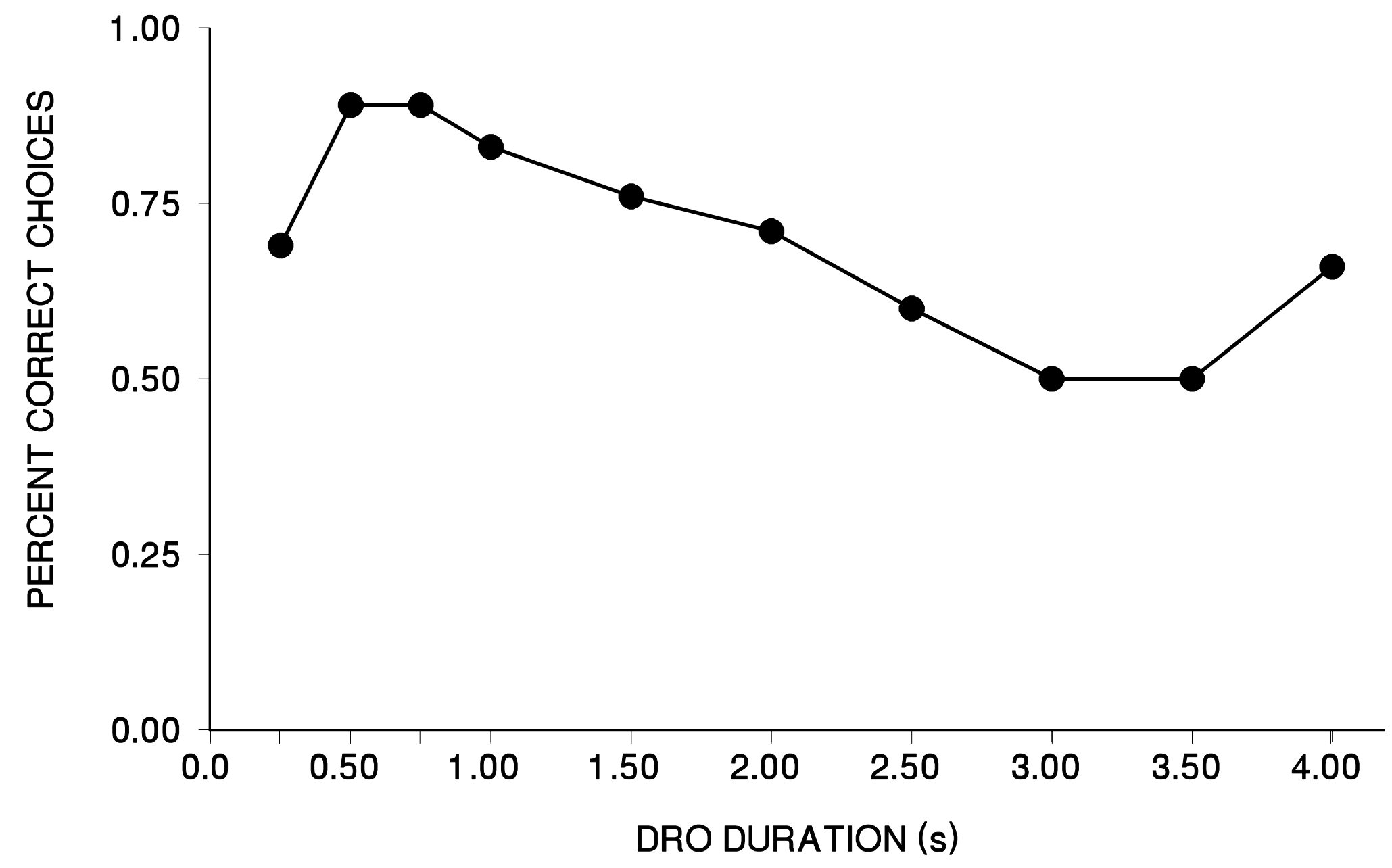




\section{Discussion}

Experiment 2 was similar to the last condition of Experiment 1 except that obtained delays between a VI response and choice onset on response-independent choice trials were controlled for by employing a DRO schedule and a third DRO choice operandum was added. Additionally, correct DRO choices were followed by food. The results of the current experiment were similar to the first. Choice accuracy was above chance. Accuracy in the second experiment may have been lower than that in the first because of the probability of a correct choice if responding was random. In each experiment choice accuracy was typically 40 to 50\% greater than chance (i.e., 90-100\% and 70-90\% for the first and second experiments respectively). The lower accuracy of the second experiment also may have been a result of the sample schedules. The tandem VT 30-s DRO 2-s schedules reduced VI response rates relative to the first experiment. Informal observation of the pigeons suggested that while there was a reduction in key pecking, there was an increase in pecking directed around the key but that did not activate the key microswitch. Control of choice responding by the sample schedules would be reduced if a DRO initiated choice component occurred while key-directed pecking was occurring.

If off-key pecking did, in fact, increase, this may account for the reduction in accuracy at long DRO values during the DRO 
probe sessions. Choice responding could have been a function of pecking and not pecking or it could have been controlled by different key-peck topographies. A key peck that closes the microswitch results in auditory, tactile, and, perhaps, spatial feedback not provided by off-key pecks. Observation indicated that keypecks that closed the microswitch were interspersed with keypecks that did not, and that bouts of each response topography did not occur independently of one another. Short DRO requirements could be met when off-key pecking was occurring. Response rates suggest that long DRO requirements could be met only when the pigeon was not oriented toward the key (i.e., preening, moving from one key to the other). This was confirmed by informal observations. Longer pauses were often characterized by behavior other than standing in front of one of the keys. Thus, if choice responding were controlled by the topography and location of the last response then long DROs may have been equivalent to a retention interval. This would account for the decrement in accuracy as DROs increased and the finding that the pigeons could accurately discriminate response-independent from response-dependent events at shorter delays than in Experiment 1. Choice responding may have been controlled not by the response reinforcer relations per se, but rather primarily by the response topography, and then by location. This interpretation would also explain the findings reported by Nussear and Lattal 
(1983) which were somewhat different from those of Killeen (1978) and the current Experiment 1. Nussear and Lattal demonstrated accurate choice responding to a "response-dependent" and a "response-independent" choice with delays of $0.2,0.8$, and $1.0 \mathrm{~s}$. The use of a DRO schedule to arrange choice components may have resulted in different response topographies serving a discriminative function as opposed to the response-reinforcer dependency. The results of the current Experiment 2 and those of Nussear and Lattal, suggest that the aspects of a contingency serving a discriminative function are determined by the schedules employed. The temporal contiguity between responding and a reinforcer served a discriminative function in Killeen's experiment and the current Experiment 1. The topography of a response may have served a discriminative function in Nussear and Lattal's (1983) procedure and the current Experiment 2. Control by the topography of responding was not exclusive as is evident by the better than chance accuracy in each experiment at all DRO values. 


\section{General Discussion}

The present experiments demonstrate control of choice responding by the response-reinforcer relations generated by concurrent schedules arranging both response-dependent and response-independent events. Responding during the choice component of a conditional discrimination was a function of the schedule of reinforcement that arranged that component. Disruptions in temporal contiguity and the local responsereinforcer relations either disrupted responding to the responsedependent choices or controlled responding to a responseindependent choice.

Sidman (1980) suggested that 75\% accuracy in conditional discrimination and matching-to-sample procedures may be an insufficient accuracy criterion. He noted that a number of possible combinations of correct and incorrect choices in a twochoice procedure will result in an overall accuracy measure of 75\%. Some of these combinations do not necessarily reflect "accurate" choice responding, such as 100\% correct after one sample and 50\% correct after a second sample. Such a combination would indicate that only one of two stimuli was serving a discriminative function. The current Experiment 1 is not subject to this criticism as accuracy remained at or above $90 \%$ for all but one condition for one pigeon. The accuracy measures for all pigeons in Experiment 2 at stability were approximately 75\%. 
Sidman's concern also does not apply to Experiment 2, however, for two reasons. First, and more importantly, the error analysis indicates that there was not one type of choice component that resulted in consistently more errors than the others. The second reason is that a three-choice procedure was used. This means that random choice responding would result in accuracy measures of 33\%. The obtained accuracy scores were 40\% above chance on average. This is equivalent, in absolute terms, to accuracy scores of $90 \%$ on a two choice procedure of the sort used by Sidman to exemplify the problems of percent correct in measuring conditional discrimination performance.

Alsop and Davison (1992) and Jones and Davison (1998) suggested that concurrent schedule performance is a function of the discriminability of the source(s) of reinforcement. Their procedures, however, offered equivocal support for their contention, as noted in the literature review above. Specifically, control of choice responding in their studies may have been a function of the response-reinforcer relations arranged by their sample VI schedules or of the schedulecorrelated stimuli they employed. The present experiments eliminated schedule-correlated visual stimuli but could not eliminate spatial or topographical ones. Control of choice responding in the first part of Experiment 1 could have been by the response-reinforcer relations or by the spatial location of 
the pigeon. The introduction of a response-independent choice response in the last part of Experiment 1 and Experiment 2 suggests that choice responding was not merely a function of the spatial cues but of the discriminative properties of the programmed response-reinforcer relations. Had choice been under the control of the pigeons' location in the chamber, differential responding on VT- and DRO- produced choice components would not have developed. Rather, responding would have occurred to the left-VI-produced or right-VI-produced choice alternatives according to where the pigeon was located just prior to the onset of the response-independent choice component.

The pigeon's location in the experimental chamber should not be viewed as a confounding variable but as a necessary, and perhaps inseparable, part of concurrent schedule performance. Furthermore, the pigeon's beak was touching one of the keys when a VI-arranged choice was presented and generally not when a VTor DRO-produced choice component was presented. The resulting discrimination would be a spatial discrimination. The introduction of VT choices in Experiment 1 controlled responding to the left and right VI choices at short delays. This finding requires that the spatial discrimination be conceptualized as near the left key, near the right key, or other. It therefore seems more parsimonious to interpret the current results in terms of temporal contiguity, which allows more precise specification 
of the discriminative stimuli (e.g., delay in seconds as opposed to "near the key").

Control of choice responding by the concurrent VI schedules in the current experiments adds support to the findings of Alsop and Davison (1992) and Jones and Davison (1998). The present results offer stronger evidence that choice responding in their experiments was controlled not only by the schedule-correlated stimuli but also by the local response-reinforcer relations generated by the concurrent VI schedules.

Lattal (1975, 1979), Killeen (1978, 1981), Nussear and Lattal (1983), and Warner (1990) all attempted to control conditional discrimination choice responding by the discriminative properties of schedules arranging responsedependent and response-independent food presentations. The reinforced response during a choice component was dependent upon the source of the previous reinforcer. Only Warner was unable was unable to establish control of choice responding by the source of the previous reinforcer. Warner's negative results are not surprising because there can be no difference between, for example, a response followed 2 s later by a response-dependent food presentation and a response followed 2 s later by a response-independent food presentation.

Lattal $(1975,1979)$ reinforced choice responding according to whether a choice response was arranged by a DRL 10-s or a DRO 
10-s schedule. Lattal's procedure does not allow the individual effects of the response-reinforcer dependency to be separated from the presence or absence of contiguity. Whether responding was a function of the dependency or of the temporal proximity between the two therefore is not known. Killeen (1978) reinforced choice responding dependent on whether a choice component was arranged by a random-ratio or a random-interval schedule. He found that responding was better predicted by the time between a choice and the last response than by whether or not the choice was contingent upon responding.

The current experiments attempted to further elucidate the separate effects of the contingency between responding and a reinforcer and the contiguity between a response and a reinforcer. The introduction of VT-produced choice components in Experiment 1 allowed the contingency and the contiguity between a response and a reinforcer to vary across trials. Responding during choice components was limited to the left and right "VIproduced" choices available in the previous 5 conditions. This forced the pigeons to respond as if their behavior had produced all reinforcers. The fact that at brief delays choice responding reliably corresponded to the last VI response made and that at longer delays choice responding was seemingly random indicates that events that were more temporally contiguous were treated as if they were also contingent. 
The addition of a separate response key that corresponded to DRO- or VT-produced choices at the end of Experiment 1 and during Experiment 2 allowed the assessment of the point at which disruptions in contiguity no longer controlled responding to the VI choice alternatives. Choice responding during Experiment 1 indicated that at brief delays (between 0.2 and $0.5 \mathrm{~s}$ ), responseindependent events controlled responding as if they were response-dependent events. Longer delays produced graded shifts from reporting that an event was a function of responding to reporting that responding was a function of something other than responding. Killeen (1978, 1981) reported similar findings except that he found that pigeons reported "I caused it" at longer delays than did the current procedures.

Warner (1990) demonstrated that two response-reinforcer relations that result in equal contiguity are treated as identical irrespective of the presence or absence of the response-reinforcer dependency. Lattal (1975, 1979) and Killeen (1978) found that events that are both response-dependent and contiguous are discriminable from events that occur independently of a response and that are not contiguous with that response. The current results add to these add to these findings by demonstrating that response-independent outcomes are treated as dependent or independent based not on their lack of dependency on behavior but on their temporal proximity to behavior. This is 
apparent from the distribution of choice responses when delays between a VI response and a VT choice component were brief. Specifically, in both experiments, VT choice responses reliably corresponded to the last VI response when the VI response and choice onset were more temporally contiguous.

The finding that temporal contiguity is sufficient for judgements of causality may contribute to an understanding of mechanisms of reinforcement. Contiguity-based accounts of reinforcement, notably some interpretations of the Law of Effect, suggest that the response-strengthening effects of reinforcement are the result of temporal contiguity. Skinner (1948) stated that in superstition experiments where an animal is given food presentations independent of responding, that the "(subject) behaves as if there were a causal relation between its behavior and the presentation of food." The finding in the current experiments that pigeons' reports on choice trials were a function of VI responding when delays between a VI response and the choice trial onset were short, adds support for a contiguity based account of reinforcement. As in Skinner's experiment, pigeons behaved as if their responding caused the choice component. Taken together, these data suggest that concurrent schedule performance is not a function of average responsereinforcer relations taken across sessions but rather of the moment to moment temporal dependency between events. 
Killeen (1978) offered a similar account of choice responding. His finding of "I caused it" responses when responseindependent choices were contiguous with responding (i.e., occurred within $0.8 \mathrm{~s}$ of a response) "indicate(s) that pigeons are accurate in their perception of contingencies between behavior and environment, and that the discrimination...was probably based on the delay between a response and its effects." It would seem more accurate to say that responding was based on the delay between a response and a stimulus change because there were no programmed consequences between an adventitiouslyreinforced response and stimulus changes.

The present results, in concert with previous ones, suggest that the discriminative properties of the response-reinforcer relation are primarily a function of temporal contiguity between a response and food delivery. The topography of responding or schedule-correlated stimuli, whether they are lights or the subject's location in the chamber, also may serve a discriminative function, but these aspects of schedules are arbitrary in the sense that they are a function of the specific arrangement of the programmed schedules and the apparatus used. The response-reinforcer dependency dictated by the schedule employed determines the pattern and topography of responding but it is the temporal relation between responding and reinforcer presentation that controls the discriminative properties of the 
schedule. 


\section{REFERENCES}

Alsop, B., \& Davison, M. (1991). Effects of varying stimulus disparity and the reinforcer ratio in concurrent-schedule and signal-detection procedures. Journal of the Experimental Analysis of Behavior, 56, 67-80.

Alsop, B., \& Davison, M. (1992). Discriminability between alternatives in a switching-key concurrent schedule. Journal of the Experimental Analysis of Behavior, 57, 51-65.

Davison, M., \& McCarthy, D. (1988). The Matching Law: A Research Review. New Jersey: Erlbaum.

Dougherty, D. H., \& Wixted, J. T. (1996). Detecting a nonevent: Delayed presence-versus-absence discrimination in pigeons. Journal of the Experimental Analysis of Behavior, 65, $81-92$

Findley, J. D. (1958). Preference and switching under concurrent scheduling. Journal of the Experimental Analysis of Behavior, 1, 123-144.

Fleshler, M., \& Hoffman, H. S. (1962). A progression for generating variable-interval schedules. Journal of the Experimental Analysis of Behavior, 5, 529-530.

Gewirtz, J. L. (1997). The response-stimulus contingency and reinforcement learning as a context for considering two nonbehavior-analytic views of contingency learning. The Behavior Analyst, 20, 121-128. 
Jones, B. M., \& Davison, M. (1998). Reporting contingencies of reinforcement in concurrent schedules. Journal of the Experimental Analysis of Behavior, 69, 161-183.

Killeen, P. R. (1978). Superstition: A matter of bias not detectability. Science, 199, 88-89.

Killeen, P. R. (1981). Learning as causal inference. In Commons, M. L. \& Nevin, J. A. (Eds.), Quantitative Analyses of Behavior. (pp. 113-133). New York: Harper \& Row, Publishers, Inc. Lattal, K. A. (1973). Response-reinforcer dependence and independence in multiple and mixed schedules. Journal of the Experimental Analysis of Behavior, 20, 265-271.

Lattal, K. A. (1974). Combinations of response-reinforcer dependence and independence. Journal of the Experimental Analysis of Behavior, 22, 357-362.

Lattal, K. A. (1975). Reinforcement contingencies as discriminative stimuli. Journal of the Experimental Analysis of Behavior, 23, 241-246.

Lattal, K. A. (1979). Reinforcement contingencies as discriminative stimuli: II. Effects of changes in stimulus probability. Journal of the Experimental Analysis of Behavior, $31,15-22$.

Lattal, K. A. (1981). Reinforcement contingencies as discriminative stimuli. In Commons, M. L. \& Nevin, J. A. (Eds.), Quantitative Analyses of Behavior. (pp. 113-133). New York: 
Harper \& Row, Publishers, Inc.

Nussear, V. P., \& Lattal, K. A. (1983). Stimulus control of responding by response-reinforcer temporal contiguity. Learning and Motivation, 14, 472-486.

Pliskoff, S. S., \& Goldiamond, I. (1966). Some discriminative properties of fixed ratio performance in the pigeon. Journal of the Experimental Analysis of Behavior, 9, 1-9. Reynolds, G. S. (1966). Discrimination and emission of temporal intervals by pigeons. Journal of the Experimental Analysis of Behavior, 9, 65-68.

Shimp, C. P. (1981). The local organization of behavior: Discrimination of and memory for simple behavioral patterns. Journal of the Experimental Analysis of Behavior, 36, 303-315. Shimp, C. P. (1983). The local organization of behavior: Dissociations between a pigeon's behavior and self-reports of that behavior. Journal of the Experimental Analysis of Behavior, $39,61-68$.

Sidman, M. (1980). A note on the measurement of conditional discrimination. Journal of the Experimental Analysis of Behavior, 33, 285-289.

Skinner, B. F. (1948). Superstition in the pigeon. Journal of Experimental Psychology, 38, 168-172.

Stubbs, A. (1968). The discrimination of stimulus duration by pigeons. Journal of the Experimental Analysis of Behavior, 11, 
$223-238$.

Stubbs, D. A. (1976). Response bias and the discrimination of stimulus duration. Journal of the Experimental Analysis of Behavior, 25, 243-250.

Stubbs, D. A., \& Pliskoff, S. S. (1969). Concurrent responding with fixed relative rate of reinforcement. Journal of the Experimental Analysis of Behavior, 12, 887-895.

Warner, J. E. (1990). The discrimination of delayed and response-independent events. Unpublished Masters Thesis: West Virginia University.

Zeiler, M. D. (1976). Positive reinforcement and the elimination of reinforced responses. Journal of the Experimental Analysis of Behavior, 26, 37-44. 


\section{Appendix A. Computer Programs}

$\underline{\text { Experiment } 1}$

Concurrent chains schedule. VI120 FR5

Baseline program for conditional discrimination study

CConcurrent interdependent VI 60-s schedules on the left and right keys

Iproduce choice trial where two keys are lit; one red, one green. Color is randomly assigned to the two keys. When the

lleft VI produces the choice trial red will be followed by $4 \mathrm{~s}$ access

Ito food. Green pecks will be reinforced when the right key produced

the choice. Food is delivered according to FR 5 schedules. Incorrect

lchoices (i.e. red when right) will be followed by a 3-s BO at which point

Ithe key that produced the choice will be illuminated. The next choice

Itrial will begin after five responses to the illuminated VI key VI keys, Iwhen illuminated are always white. The session will end after 40 reinforcers.

$\wedge \mathrm{hl}=3$

$\wedge$ hopper $=8$

^lwhite $=9$

^bgreen $=10$

^rwhite $=18$

$\wedge$ bred $=15$

^tred $=16$

^tgreen $=17$

$\backslash \wedge$ cgreen $=12$

$\backslash \wedge$ cred $=2$

$\backslash \wedge$ cwhite $=3$

$\backslash \wedge$ lgreen $=4$

$\backslash \wedge$ lred $=5$

$\backslash \wedge$ lwhite $=6$

\^hl $=7$

$\backslash \wedge$ hopper $=8$

$\backslash \wedge$ rgreen $=10$

$\backslash \wedge$ rred $=9$

\^rwhite $=11$ 


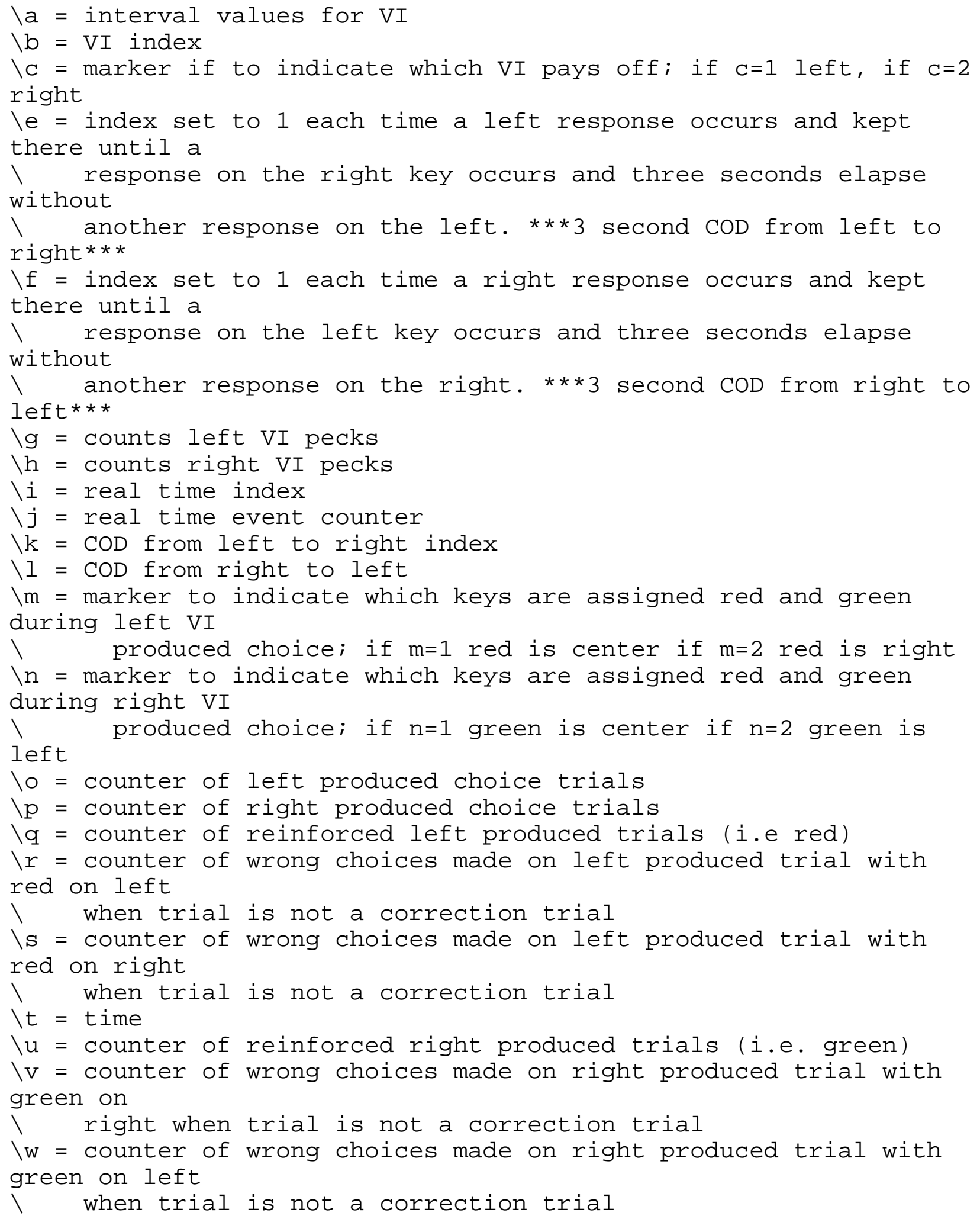


$\backslash \mathrm{x}=$ marker to indicate when an error on left produced trial was immediately

1 proceded by another error on a left produced trial; reset after an

$\backslash$ accurate correction trial

$\backslash y=$ marker to indicate when an error on right produced trial was immediately

$\backslash$ proceded by another error on a right produced trial; reset after an

1 accurate correction trial

$\backslash z=$ array for show of events

$\backslash z(1)=$ counter of wrong choices on left produced trial with red on left

$\backslash$ when trial is a correction trial

$\backslash z(2)=$ counter of wrong choices on left produced trial with red on right

$\backslash$ when trial is a correction trial

$\backslash z(3)=$ counter of wrong choices on right produced trial with green on right

$\backslash$ when trial is a correction trial

$\backslash z(4)=$ counter of wrong choices on right produced trial with green on left

$\backslash$ when trial is a correction trial

$\backslash 1=$ left $\mathrm{VI}$ peck

Show lines on screen

$\backslash 2$ = right VI peck

$\backslash 3$ = left VI produced choice trials

$\backslash 4$ = right VI produced choice trials

$\backslash 5=$ reinforced left produced choice trials

$\backslash 6$ = reinforced right produced choice trials

$\backslash 7$ e errors on left produced choice with red on left

$\backslash 8=$ errors on left produced choice with red on right

$\backslash 9=$ errors on right produced choice with green on right

$\backslash 10=$ errors on right produced choice with green on left

$\backslash 11$ = total time

$\backslash 12$ e errors on left produced choice with red on left when trial is a

$\backslash$ correction trial

$\backslash 13$ = errors on left produced choice with red on right when trial is a

$\backslash$ correction trial

$\backslash 14$ e errors on right produced choice with green on right when

trial is a

$\backslash$ correction trial

$\backslash 15$ = errors on right produced choice with green on left when trial is a

I correction trial 


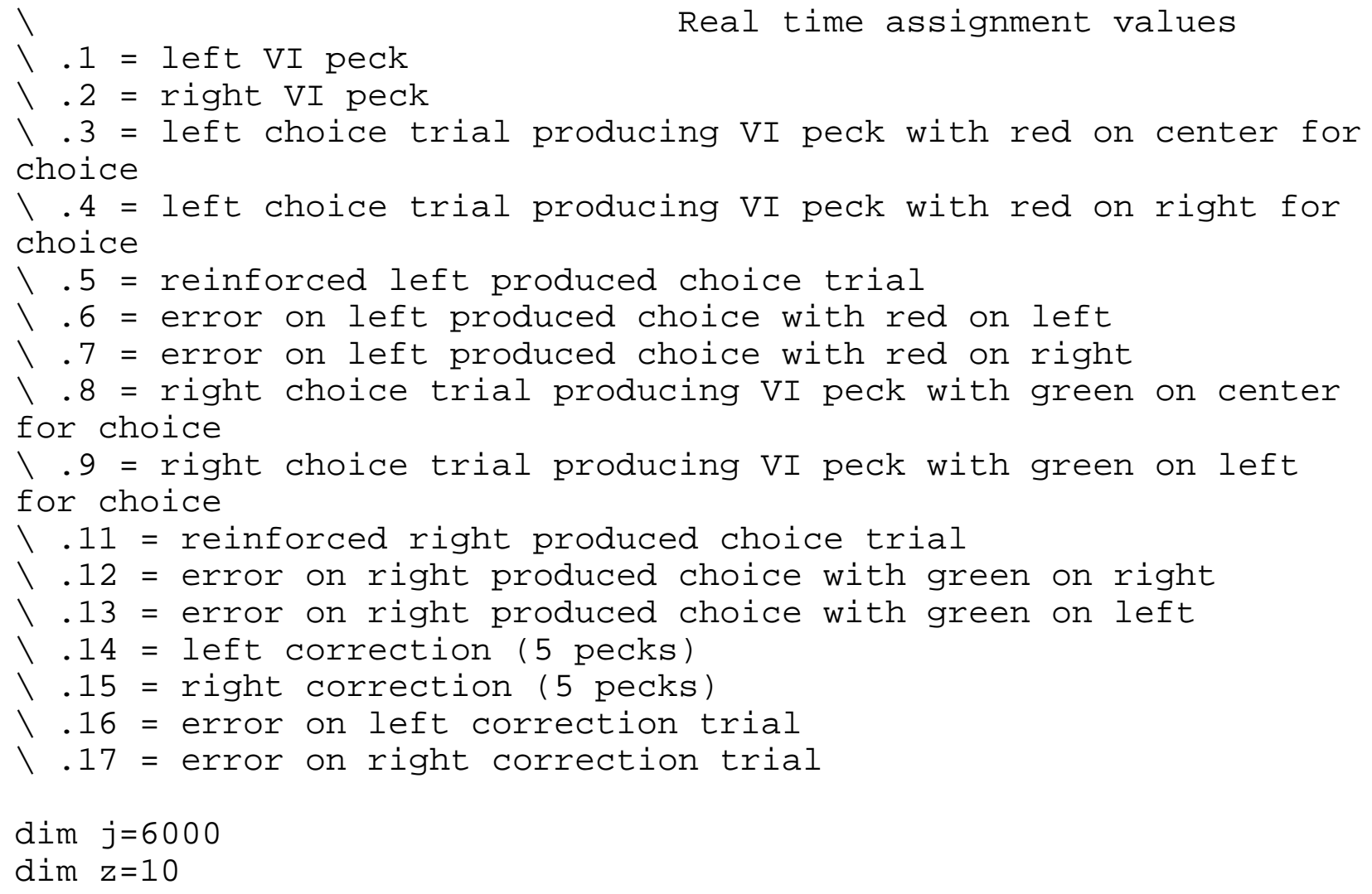

$\backslash$ GUTS

S.S.1, \starts session and assigns VI values to left and right and

$\backslash$ decides which VI will produce choice trial

s1,

\#start: on ^hl, ^lwhite, ^rwhite; randd b=a--->s2 
s2, \ counts VI pecks, times out VI and assigns VI to left or right

\#r2: add $g ;$ show 1 , leftVI, $g$; set $j(i)=t+.1$; add $i$; set $j(i)=-987.987--->s x$

\#r3: add h; show 2, rightVI, $h$; set $j(i)=t+.2$; add $i$; set $j(i)=-987.987--->s x$

b \#t: with pi=5000 [atop, abottom] /assigns timed out VI to left or right

dtop: set $c=1--->$ s3

Qbottom: set $\mathrm{C}=2--->\mathrm{s} 9$

s3, \controls left VI produced choice trial and randomly assigns red or green

\to left and right choice keys; red is payoff key

$\#$ \#3: add $h$; show 2 , rightVI, $h$; set $j(i)=t+.2$; add $i$; set $j(i)=-$ $987.987--->$ s13

\#r2: if $f=1$ [@wait, @go]

(dwait:add 9 ; show 1 , leftVI, $g$; set $j(i)=t+.1$; add i; set $j(i)=-987.987--->s x$

@go: with pi $=5000$ [atred, abred]

etred:add 9 ; show 1, leftVI, g; add o; show 3,

lchoice, o;

set $\mathrm{m}=1$;

off ^lwhite, ^rwhite; on ^tred, ^bgreen;

$>s 4$

lchoice, o;

abred:add g; show 1, leftVI, g; add o; show 3,

set $\mathrm{m}=2$;

$>s 5$

off ^lwhite, ^rwhite; on ^bred, ^tgreen;

set $j(i)=t+.4 ;$ add $i$; set $j(i)=-987.987---$

s4, \left produced choice trial with red on top key

3 \#rl: off ^hl, ^tred, ^bgreen; on ^hopper; add q; show 5, lrein, q;

set $j(i)=t+.5 ;$ add $i$; set $j(i)=-987.987$; randd $b=a$; set

$\mathrm{m}=0$;

set $c=0 ;$ set $\mathrm{x}=0--->\mathrm{s} 12$

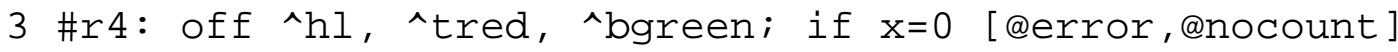

add i

derror:add $r ;$ show 7 , lerrt, $r$; set $j(i)=t+.6$; 


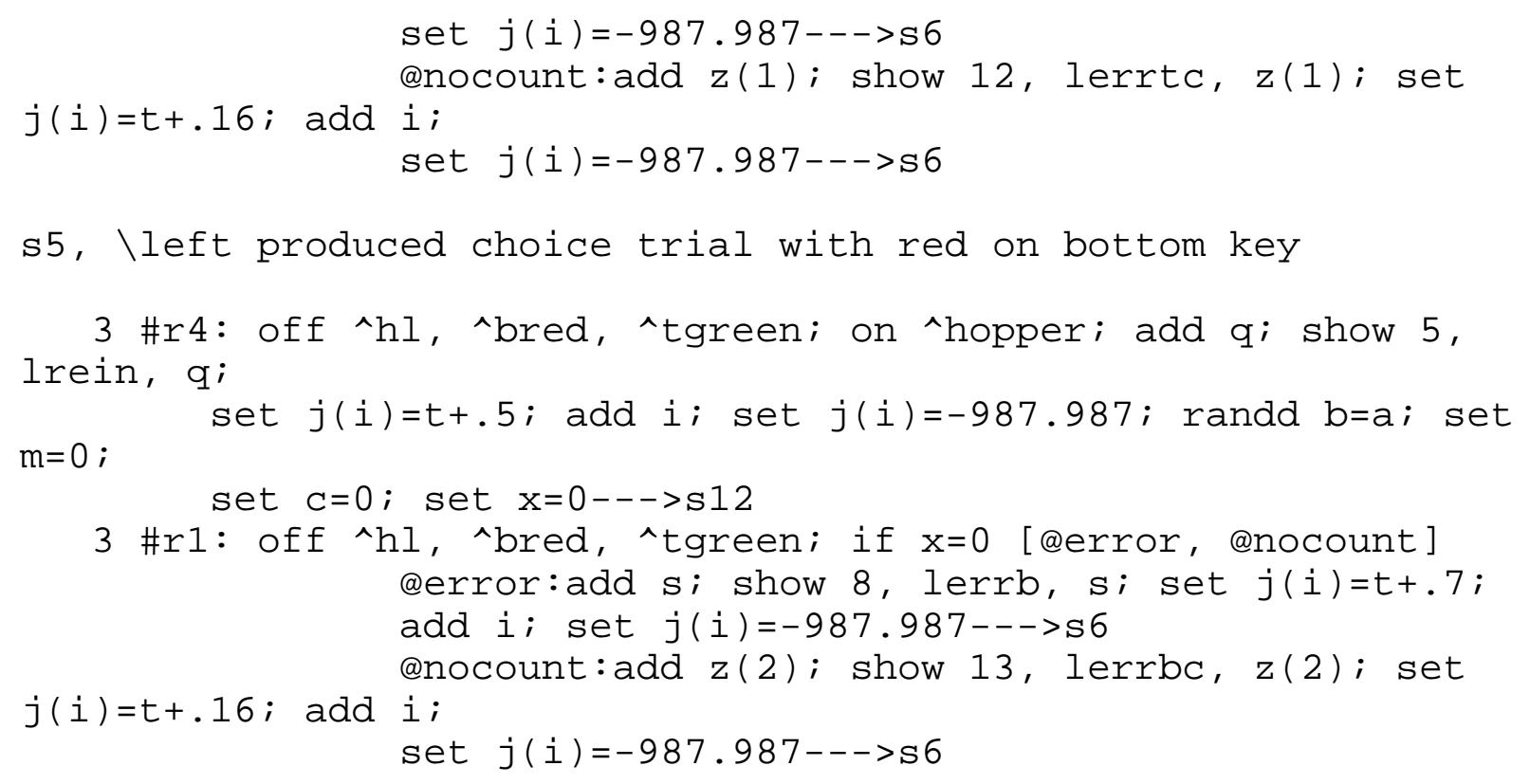

s7, \FR5 on left VI after correction to return to choice

$4 \# r 2$ : set $x=1 ;$ set $j(i)=t+.14 ;$ add $i ; \operatorname{set} j(i)=-987.987--->s 3$

s8, \ FR5 on right VI after correction to return to choice

4 \#r3:set $y=1 ;$ set $j(i)=t+.15 ;$ add $i ; \operatorname{set} j(i)=-987.987--->s 9$

s9, \controls right VI produced choice trial and randomly assigns red or green

tto right and left choice keys; green is payoff key

$\#$ 22: add gishow 1 , leftVI, gi set $j(i)=t+.1 ; \operatorname{add} i ; \operatorname{set} j(i)=-$ $987.987--->$ s 14

\#r3: if e=1 [@wait, @go]

@wait:add h; show 2, rightVI, h; set $j(i)=t+.2$; addi; set $j(i)=-987.987--->s x$ 


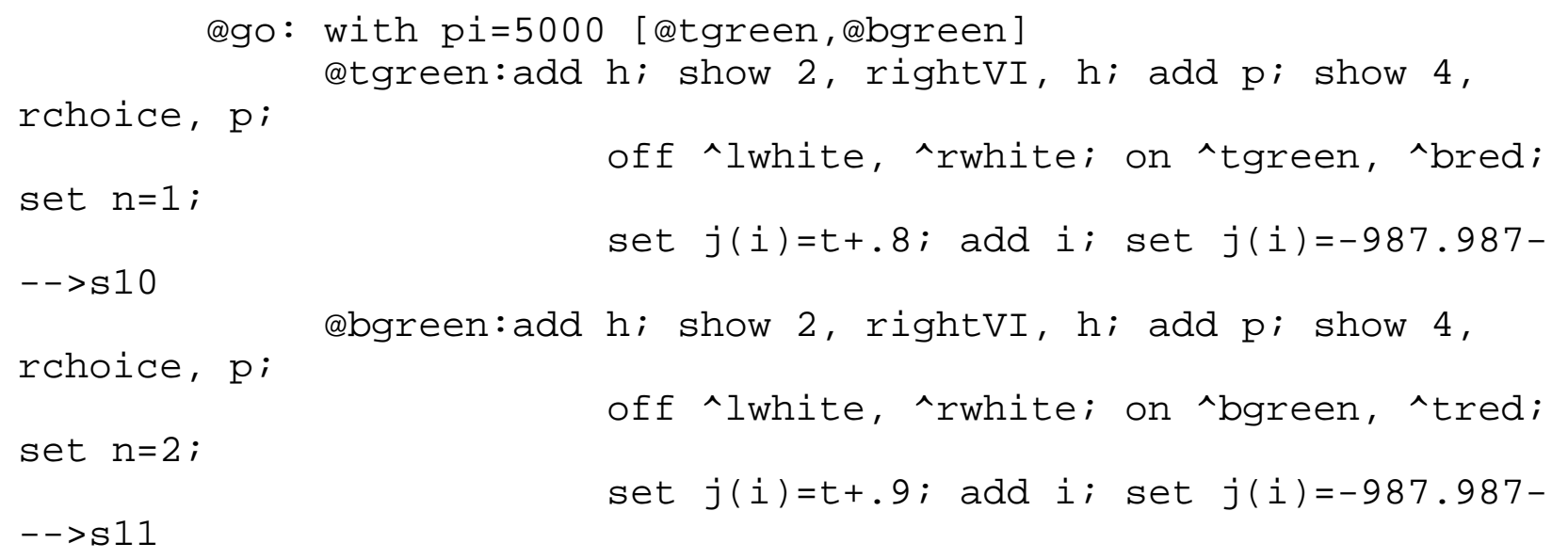


@go: on ^hl, ^rwhite, ^lwhite--->s2

s13, \cod for left trials

$3 ":--->s 3$

\#r2: add gishow 1, leftVI, giset $j(i)=t+.1$; add $i$ iset $j(i)=-$ $987.987--->$ sx

$\# r 3$ : add $h ;$ show 2 , rightVI, $h$; set $j(i)=t+.2$; add $i$; set $j(i)=-$ $987.987--->$ s 15

s14, \cod for right trials

$3 ":--->s 9$

$\#$ \#2:add g; show 1 , leftVI, g; set $j(i)=t+.1 ; \operatorname{add} i ; \operatorname{set} j(i)=-$ $987.987--->$ s 16

$\# r 3$ : add h; show 2, rightVI, h; set $j(i)=t+.2$; addi; set $j(i)=-$ $987.987--->s x$

s15,

$.01 ":--->s 13$

s16,

$.01 ":--->s 14$

S.S.2, \Session timer

S1,

\#start: $--->$ s2

S2,

$.1 "$ : add $t ;$ show 11, t_time, t/600 --->sx

\section{Experiment 2}

$\backslash \quad$ Training program for dissertation Experiment 2.

!

I Concurrent interdependent VI 30-s VI 30-s tandem VT $\mathrm{x}-\mathrm{s}$ DRO 2-s

( schedules. Two side keys are illuminated white. Completion of

operative schedule requirement results in two side keys and the 


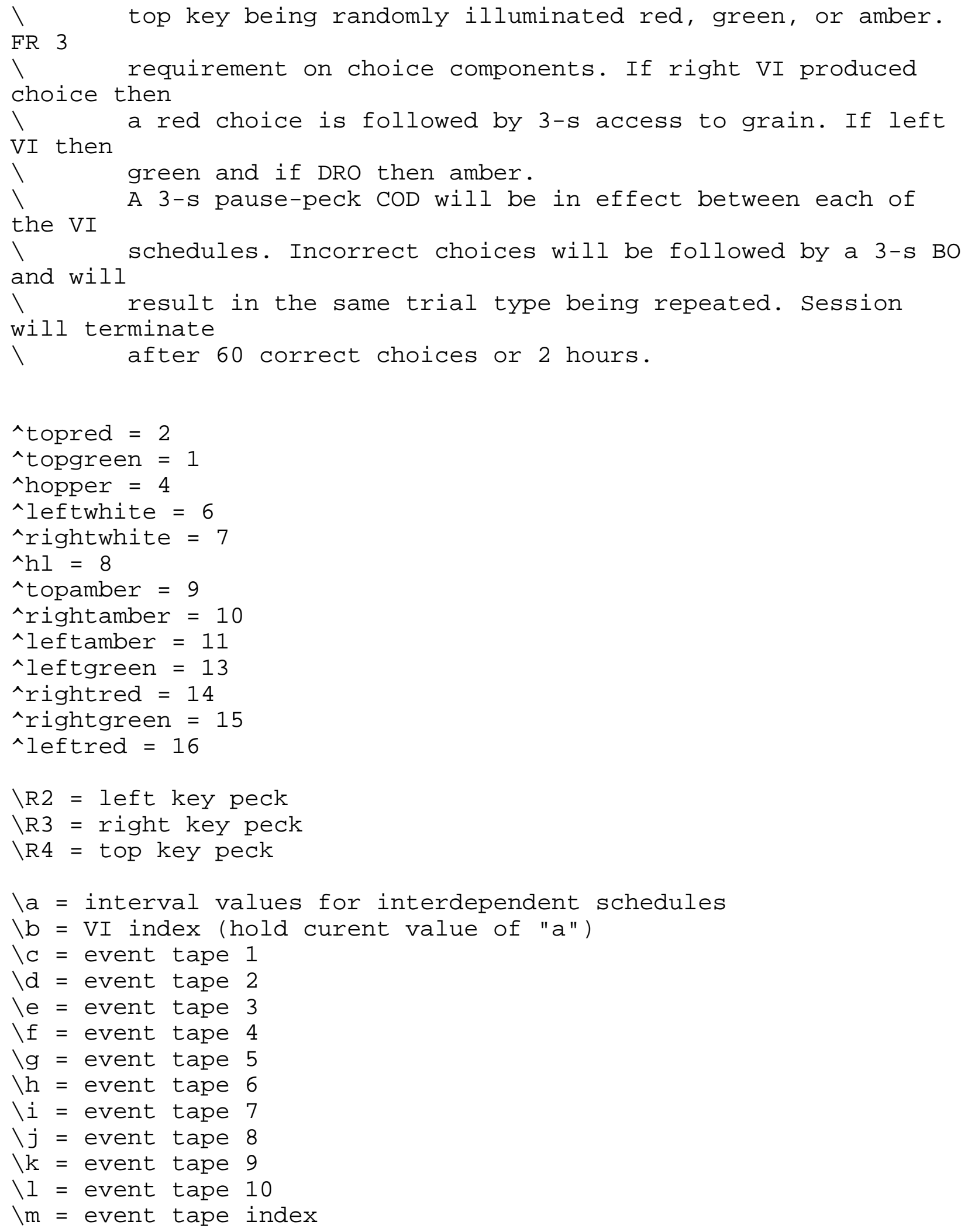




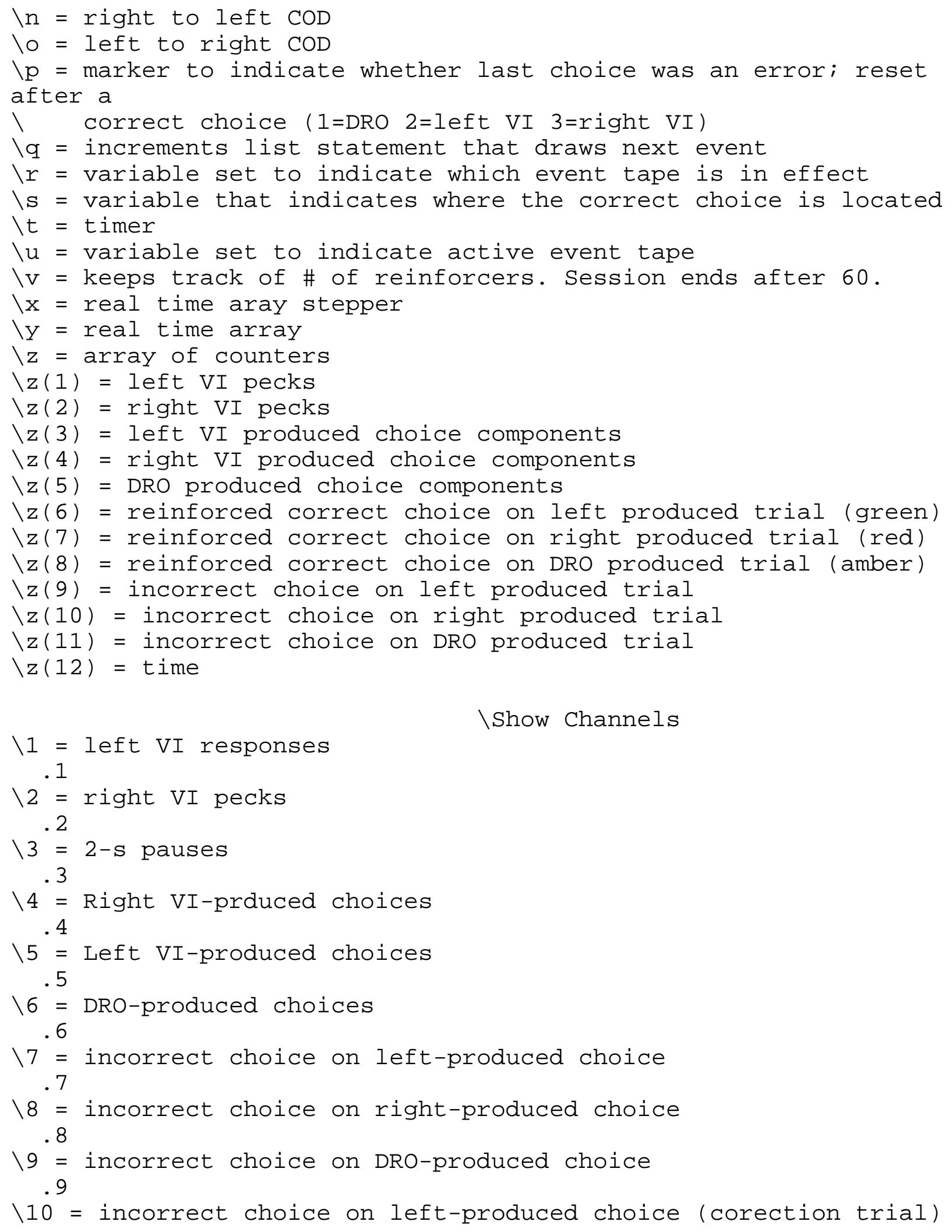




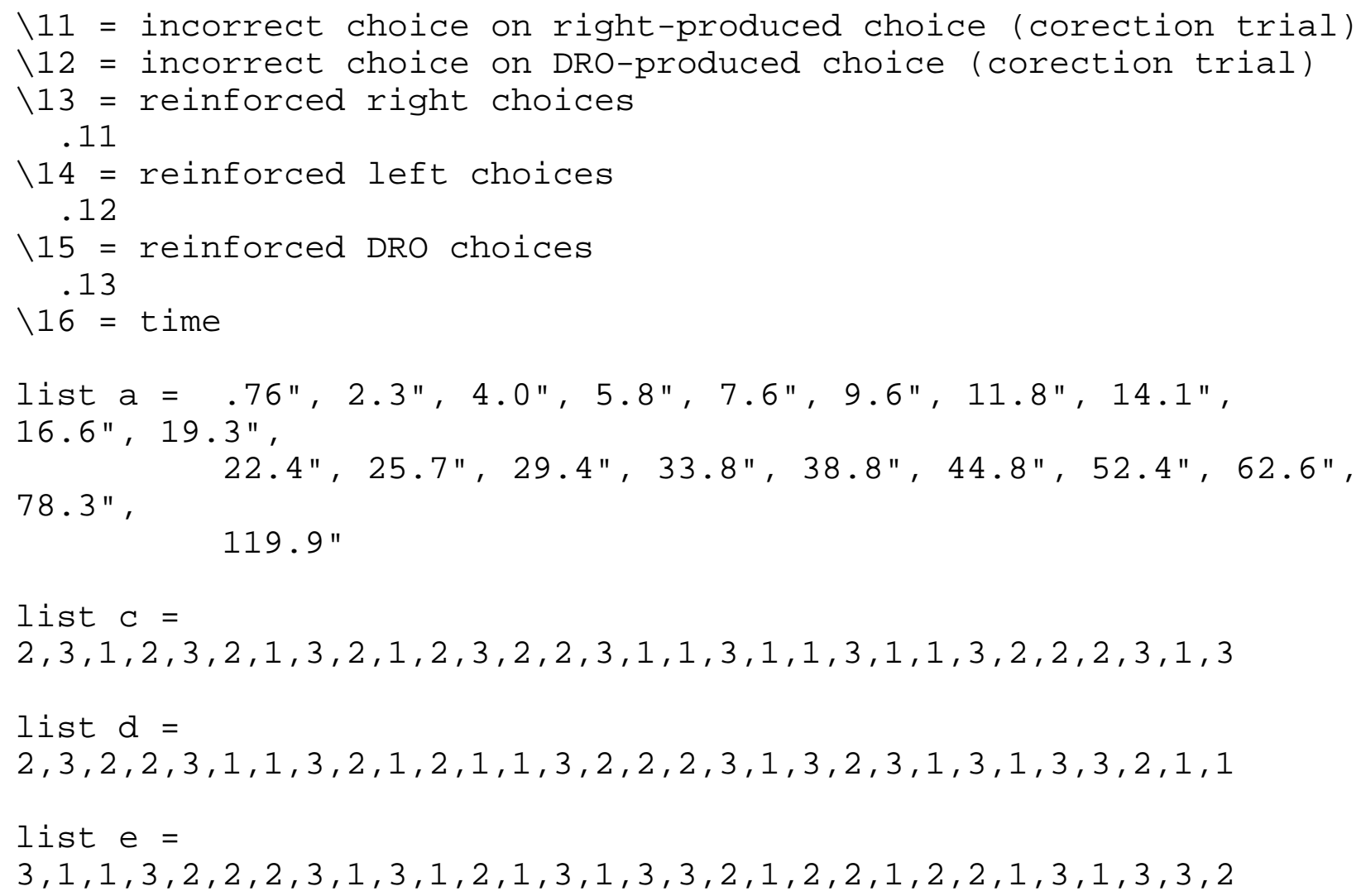




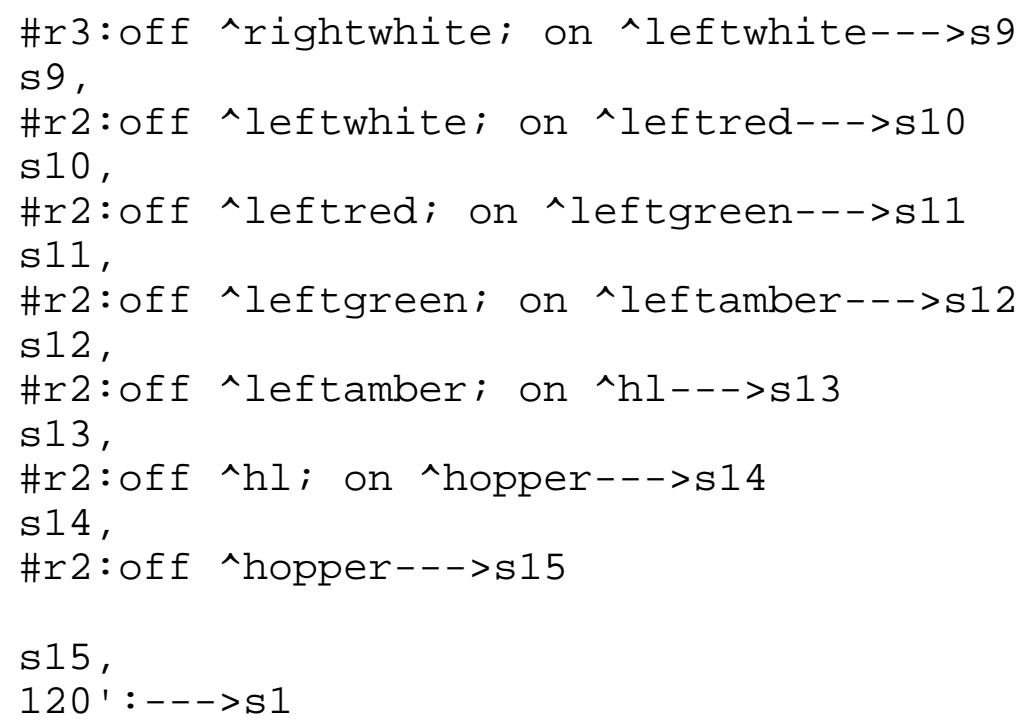

S.S.2, \selects tape to use, next interval duration and sends $z^{-}$ pulse to

lstart state set for left VI, right VI, or DRO

s1,

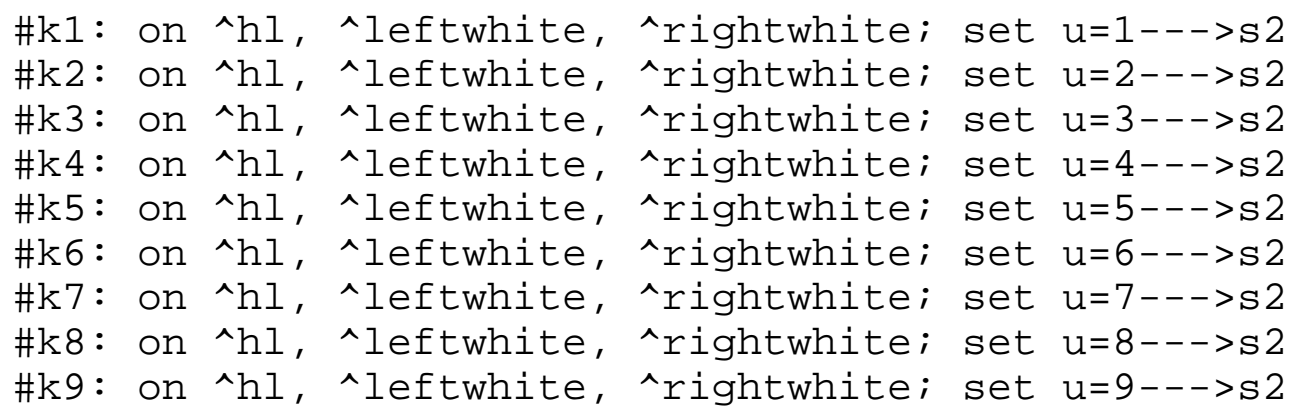

\#k10: on ^hl, ^leftwhite, ^rightwhite; set u=10--->s2

s2,

$.001 "$ : if $(p=1)$ or $(p=2)$ or $(p=3)$ [@correction, @newtrial]

dcorrection: randd $\mathrm{b}=\mathrm{a}--->\mathrm{s} 3$

anewtrial: if $u=1$ [ atape1, eother]

Qtape 1: randd $\mathrm{b}=\mathrm{a}$; list $\mathrm{m}=\mathrm{c}(\mathrm{q})--->\mathrm{s} 3$

@other: if $u=2$ [@tape2, @other]

atape 2: randd $\mathrm{b}=\mathrm{a}$; list $\mathrm{m}=\mathrm{d}(\mathrm{q})--->\mathrm{s} 3$

eother: if $u=3$ [etape3, eother]

atape 3: randd $\mathrm{b}=\mathrm{a}$; list $\mathrm{m}=\mathrm{e}(\mathrm{q})--->\mathrm{s} 3$

eother: if $u=4$ [@tape4, eother]

atape 4: randd $\mathrm{b}=\mathrm{a}$; list $\mathrm{m}=\mathrm{f}(\mathrm{q})--->\mathrm{s} 3$

@other: if $u=5$ [atape5, eother] 
atape 5: randd $\mathrm{b}=\mathrm{a}$; list $\mathrm{m}=\mathrm{g}(\mathrm{q})--->\mathrm{s} 3$

dother: if $u=6$ [ dtape6, dother]

atape 6: randd $\mathrm{b}=\mathrm{a}$; list $\mathrm{m}=\mathrm{h}(\mathrm{q})--->\mathrm{s} 3$

dother: if $u=7$ [Qtape7, eother]

etape 7: randd $\mathrm{b}=\mathrm{a}$; list $\mathrm{m}=\mathrm{i}(\mathrm{q})--->\mathrm{s} 3$

@other: if $u=8$ [@tape8, @other]

dtape 8: randd $\mathrm{b}=\mathrm{a}$; list $\mathrm{m}=\mathrm{j}(\mathrm{q})--->\mathrm{s} 3$

eother: if $u=9$ [@tape9, etape10]

dtape 9: randd $\mathrm{b}=\mathrm{a}$; list $\mathrm{m}=\mathrm{k}(\mathrm{q})--->\mathrm{s} 3$

atape10: randd $\mathrm{b}=\mathrm{a}$; list $\mathrm{m}=1(\mathrm{q})--->\mathrm{s} 3$

s3,

$\#$ \#2: add $\mathrm{z}(1)$; show 1 , leftVI, $\mathrm{z}(1) ;$ set $\mathrm{y}(\mathrm{x})=t+.1$; add $\mathrm{x}$; set $\mathrm{y}(\mathrm{x})=-987.987--->\mathrm{sx}$

\#r3: add $z(2)$; show 2, rightVI, $z(2)$; set $y(x)=t+.2$; add

$\mathrm{x}$;

set $y(x)=-987.987--->s x$

b\#t: if $(m=1)$ or $(p=1)$ [@DRO, @else]

@DRO: add $z(5)$; show 6, DROtrial, $z(5)$; set $y(x)=t+$

. 6; add $\mathrm{x}$;

set $y(x)=-987.987 ; z 1-->s 4$

delse: if $(m=2)$ or $(p=2)$ [ @leftVI, @rightVI]

aleftVI: add z(3); show 5, LVItrial, z(3); set

$y(x)=t+.5$

add $x ;$ set $y(x)=-987.987 ; z 2--->s 4$

QrightVI: add $\mathrm{z}(4)$; show 4, RVItrial, z(4); set

$y(x)=t+.4 ;$

add $x ;$ set $y(x)=-987.987 ; z 3--->s 4$

s4,

\# z $4:--->$ s 2

s.s.3, \DRO stateset

s1,

$\# z 1:--->s 2$

s2,

$\# r 2:$ add $z(1) ;$ show 1 , leftVI, $z(1) ;$ set $y(x)=t+.1$; add $x$; set $y(x)=-987.987--->$ s3

$x$;

\#r3: add $z(2) ;$ show 2, rightVI, $z(2) ;$ set $y(x)=t+.2$; add

set $y(x)=-987.987--->s 3$ 
2": z5; with pi=3333 [@Aleft, dother]

@Aleft: with pi=5000 [@redtop, egreentop]

aredtop: off ^leftwhite, ^rightwhite; on

^leftamber, ^topred,

^rightgreen; set $s=1--->s 4$

^leftamber, @greentop: off ^leftwhite, ^rightwhite; on

dother: with pi=5000 [@Atop, @Aright]

(Atop: with pi=5000 [Qredleft, @greenleft]

aredleft: off ^leftwhite, ^rightwhite; on

^topamber,

^leftred, ^rightgreen; set $s=2--->s 4$

on ^topamber,

@greenleft: off ^leftwhite, ^rightwhite;

^rightamber,

on ^rightamber,

^leftgreen, ^rightred; set $s=2--->s 4$

@Aright: with pi=5000 [@redleft, @greenleft]

aredleft: off ^leftwhite, ^rightwhite; on

^leftred, ^topgreen; set $s=3--->s 4$

@greenleft: off $\wedge$ leftwhite, ^rightwhite;

^leftgreen, ^topred; set $s=3--->s 4$

s3,

$.001^{\prime \prime}:--->s 2$

s4,

3 \# r2: if $s=1$ [@food, abadbird] ^rightred,

efood: add $v$; off $\wedge$ hl, ^leftamber, ^topred, ^topgreen, $\mathrm{z}(8) ;$ set $\mathrm{p}=0$;

^rightgreen; on ^hopper; add z(8); show 15, DRO_SR, set $\mathrm{y}(\mathrm{x})=t+.13 ;$ add $\mathrm{x}$; set $\mathrm{y}(\mathrm{x})=-987.987--->$ s5

^topred,

abadbird: off ^hl, ^leftamber, ^rightamber, ^topamber,

^rightgreen;

^topgreen, ^leftred, ^leftgreen, ^rightred,

add $\mathrm{z}(11)$; show 9, DROmiss, $\mathrm{z}(11)$; set $\mathrm{p}=1$; set $\mathrm{m}=0$;

set $\mathrm{y}(\mathrm{x})=t+.9 ;$ add $\mathrm{x} ;$ set $\mathrm{y}(\mathrm{x})=-987.987--->$ s 6

3 \#r4: if $s=2$ [afood, abadbird] ^rightred,

efood: add v; off ^hl, ^topamber, ^leftred, ^leftgreen, 
$\mathrm{z}(8) ;$ set $\mathrm{p}=0$;

^rightgreen; on ^hopper; add z(8); show 15, DRO_SR, set $\mathrm{y}(\mathrm{x})=t+.13 ;$ add $\mathrm{x}$; set $\mathrm{y}(\mathrm{x})=-987.987--->$ s5 abadbird: off ^hl, ^leftamber, ^rightamber, ^topamber, ^topred,

^rightgreen;

^topgreen, ^leftred, ^leftgreen, ^rightred,

add $\mathrm{z}(11)$; show 9, DROmiss, $\mathrm{z}(11)$; set $\mathrm{p}=1$; set $\mathrm{m}=0$;

set $\mathrm{y}(\mathrm{x})=t+.9 ;$ add $\mathrm{x}$; set $\mathrm{y}(\mathrm{x})=-987.987--->$ s 6

3 \#r3: if $s=3$ [efood, ebadbird]

afood: add v; off ^hl, ^rightamber, ^topred, ^topgreen, ^leftred,

^leftgreen; on ^hopper; add z(8); show 15, DRO_SR, $\mathrm{z}(8) ;$ set $\mathrm{p}=0$;

set $\mathrm{y}(\mathrm{x})=t+.13 ;$ add $\mathrm{x}$; set $\mathrm{y}(\mathrm{x})=-987.987--->\mathrm{s} 5$

^topred,

abadbird: off ^hl, ^leftamber, ^rightamber, ^topamber,

^rightgreen;

^topgreen, ^leftred, ^leftgreen, ^rightred,

add $z(11)$; show 9, DROmiss, $z(11)$; set $\mathrm{p}=1$; set $\mathrm{m}=0$;

set $y(x)=t+.9 ;$ add $x ;$ set $y(x)=-987.987--->$ s 6

s5,

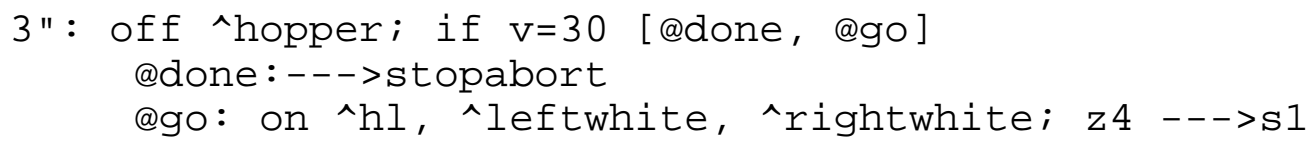

s6,

10": on ^hl, ^leftwhite, ^rightwhite; z4 --->s1

s.s.4, \Left VI stateset

s1,

$\#$ z $2:--->$ s2

s2,

$x$;

\#r3: add $z(2) ;$ show 2, rightVI, $z(2) ;$ set $y(x)=t+.2$; add set $y(x)=-987.987--->s 3$

3\#r2: z5; add $z(1) ;$ show 1 , leftVI, $z(1) ;$ set $y(x)=t+.1$; add $x$; 


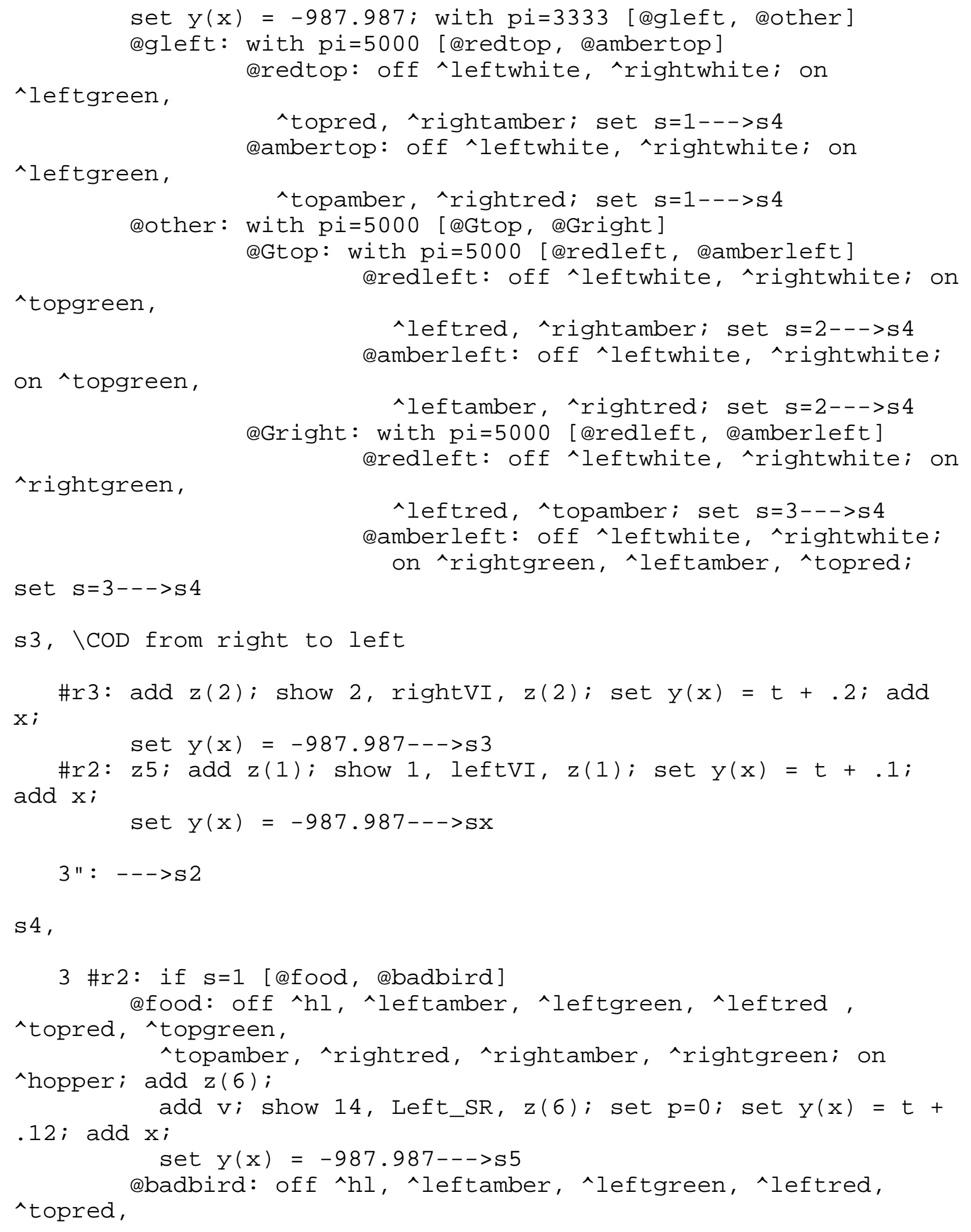




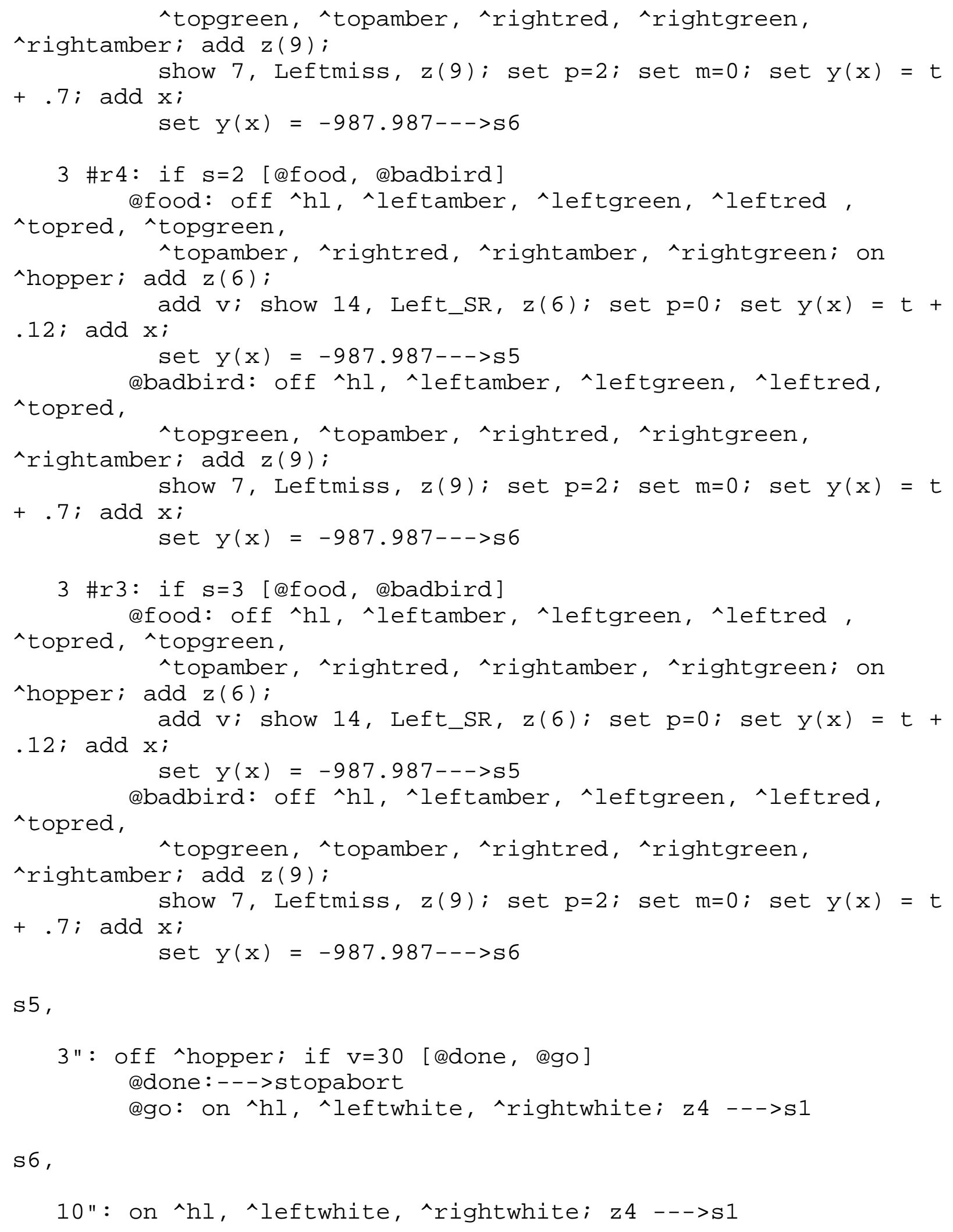




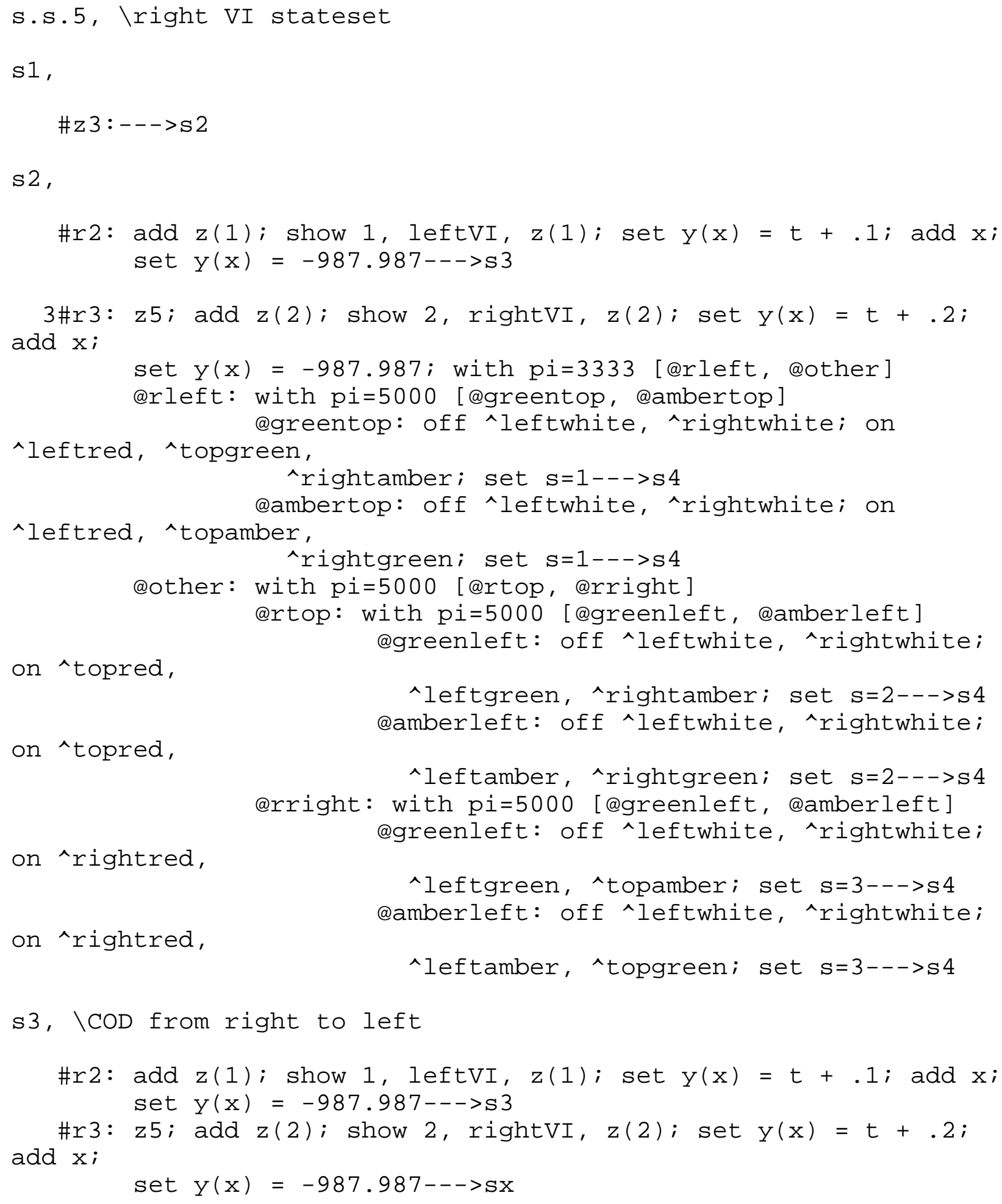


$3 ":--->s 2$

s4,

3 \#r2: if $s=1$ [afood, [badbird]

afood: off $\wedge$ hl, ^leftamber, ^leftgreen, ^leftred,

^topred, ^topgreen,

^topamber, ^rightred, ^rightamber, ^rightgreen; on

^hopper; add $\mathrm{z}(7)$;

.11 ; add $x$; add $\mathrm{v}$; show 13, Right_SR, $\mathrm{z}(7)$; set $\mathrm{p}=0$; set $\mathrm{y}(\mathrm{x})=t+$ set $\mathrm{y}(\mathrm{x})=-987.987--->\mathrm{s} 5$

abadbird: off ^hl, ^leftamber, ^leftgreen, ^leftred,

^topred,

^topgreen, ^topamber, ^rightred, ^rightgreen,

^rightamber; add z(10);

. 8; add $\mathrm{x}$; show 8, Rwrong, $\mathrm{z}(10)$; set $\mathrm{p}=3$; set $\mathrm{m}=0$; set $\mathrm{y}(\mathrm{x})=t+$ set $y(x)=-987.987--->s 6$

3 \#r4: if $s=2$ [afood, Qbadbird]

afood: off ^hl, ^leftamber, ^leftgreen, ^leftred,

^topred, ^topgreen,

^topamber, ^rightred, ^rightamber, ^rightgreen; on

^hopper; add $\mathrm{z}(7)$; add $v$; show 13 , Right_SR, $\mathrm{z}(7)$; set $\mathrm{p}=0$; set $\mathrm{y}(\mathrm{x})=t+$ $.11 ;$ add $x$;

set $y(x)=-987.987--->s 5$

abadbird: off ^hl, ^leftamber, ^leftgreen, ^leftred,

^topred,

^topgreen, ^topamber, ^rightred, ^rightgreen,

^rightamber; add z(10);

.8 ; add $\mathrm{x}$; show 8, Rwrong, $z(10) ;$ set $p=3$; set $m=0$; set $y(x)=t+$ set $y(x)=-987.987--->s 6$

3 \#r3: if $s=3$ [afood, abadbird]

afood: off ^hl, ^leftamber, ^leftgreen, ^leftred,

^topred, ^topgreen,

^topamber, ^rightred, ^rightamber, ^rightgreen; on

^hopper; add z(7); add $\mathrm{v}$; show 13, Right_SR, $\mathrm{z}(7)$; set $\mathrm{p}=0$; set $\mathrm{y}(\mathrm{x})=t+$ $.11 ;$ add $x$;

set $y(x)=-987.987--->s 5$

^topred,

abadbird: off ^hl, ^leftamber, ^leftgreen, ^leftred, 


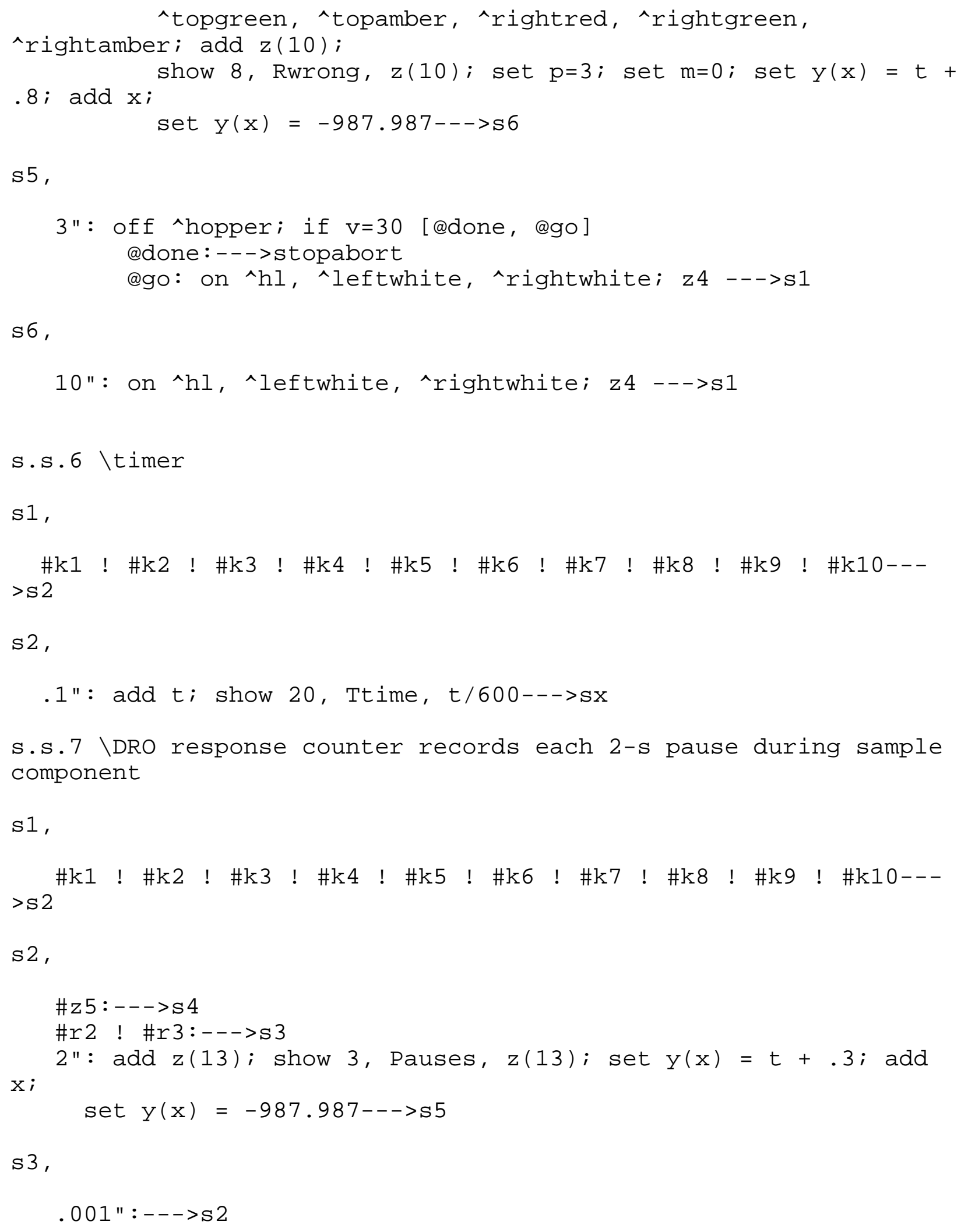


s4,

\# z $4:--->$ s 2

s5,

$\# r 2 \quad$ ! \# r3:--->s 2

S.S. 8 ,

s1,

\#k1 ! \#k2 ! \#k3 ! \#k4 ! \#k5 ! \#k6 ! \#k7 ! \#k8 ! \#k9 ! \#k10--$>\mathrm{s} 2$

s2,

$120^{\prime}:--->$ stopabort 


\section{Personal History}

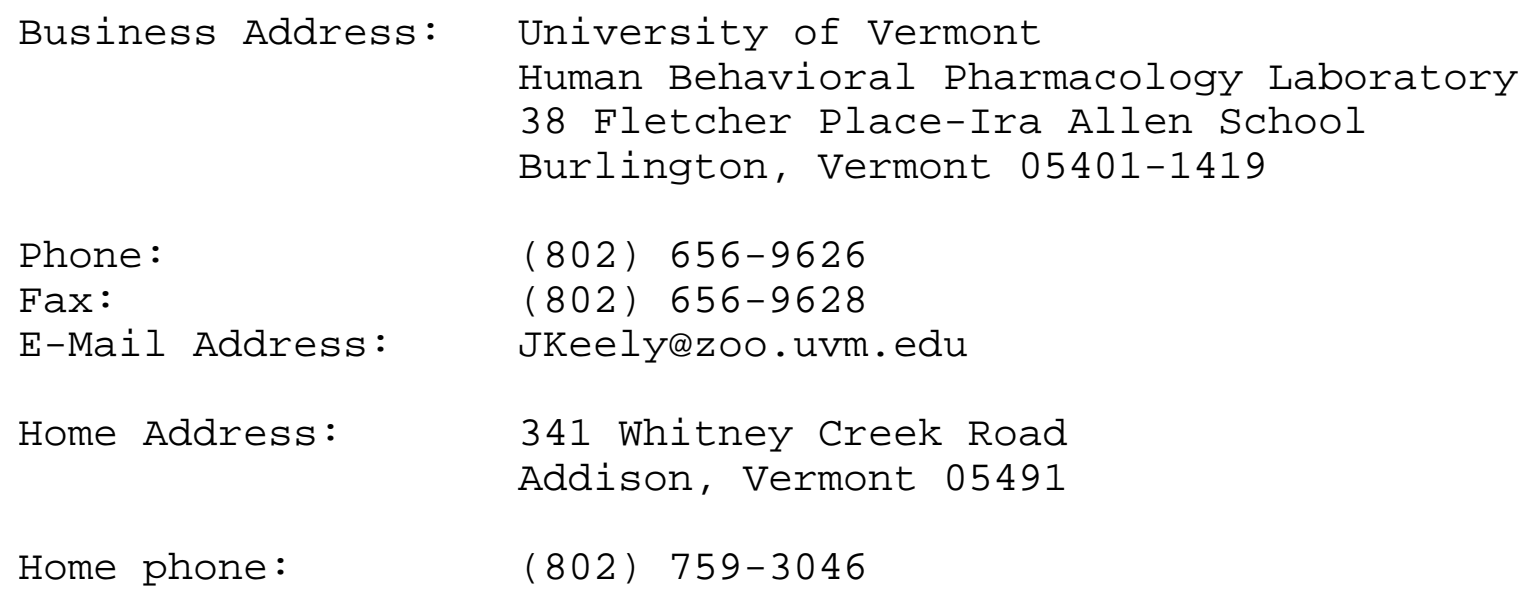

\section{Educational History}

West Virginia University

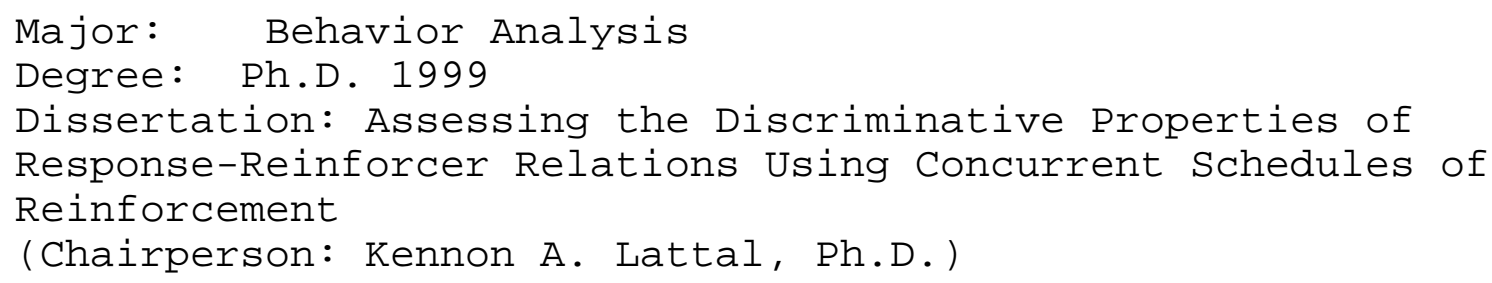

West Virginia University

Major: Behavior Analysis

Degree: M.A. 1997

Master=s Thesis: Interactions between avoidance of timeout from positive reinforcement and conjoint food schedules (Chairperson: Kennon A. Lattal, Ph.D.)

Boston University

$\begin{array}{ll}\text { Major: } & \text { Psychology } \\ \text { Degree: } & \text { B.A., Cum Laude }\end{array}$ 


\section{Professional Positions}

National Institutes of Health Post-doctoral Fellow, Human Behavioral Pharmacology Laboratory, University of Vermont, Burlington, VT, 1999-

Interventionist, Tobacco Research Center, Morgantown, WV, 19971998

Teaching Fellowship, West Virginia University, Morgantown, WV, 1994-1998

Teaching Assistant, Boston University, Boston, MA, 1993

\section{Professional Organizations}

Association for Behavior Analysis

Society for the Quantitative Analysis of Behavior

Society for Research on Nicotine and Tobacco

Southeastern Association for Behavior Analysis

\section{Professional Activities}

Graduate Student Representative to the Full Faculty Committee, Department of Psychology, West Virginia University.

Graduate Student Representative to the Behavior Analysis Training Committee, Department of Psychology, West Virginia University.

Member of Honors Thesis Committee: Resurgence of keypecking following elimination by DRO. Gregory Lieving.

Member of Honors Thesis Committee: Acquisition and Maintenance of Irrelevant Responding with Delayed Reinforcement in Rats

\section{Grants}

Psychology Department Alumni Fund, West Virginia University. Master=s thesis research grant, 1996.

Psychology Department Alumni Fund, West Virginia University. Dissertation research grant, 1998.

Eberly College of Arts and Sciences, West Virginia University. 
Dissertation research award, 1998

\section{Posters Presented at Professional Meetings}

Keely, J. P., \& Lattal, K. A. Response Acquisition Using a TwoLever Procedure: Effects of Postponement Duration. Poster presented: Association for Behavior Analysis, Orlando, FL, 1998.

Keely, J. P., \& Lattal, K. A. Discrimination of Concurrent Variable-Interval and Variable-Time Schedules in Pigeons. Poster presented: Association for Behavior Analysis, Orlando, FL, 1998.

Keely, J. P., \& Lattal, K. A. Discriminative properties of reinforcement location. Poster presented: Association for Behavior Analysis, Chicago, IL, 1997.

Keely, J. P., Miller, M. A., Parker, B. K., \& Schaal, D. W. Pavlovian facilitation by centrally acting drugs: Transfer tests without inhibition training. Poster presented: Association for Behavior Analysis, San Francisco, CA, 1996.

Keely, J. P., \& Lattal, K. A. Avoidance of timeout from positive reinforcement: Conjoint avoidance fixed-interval schedules. Poster presented: Association for Behavior Analysis, San Francisco, CA, 1996.

Miller, M. A., Keely, J. P., Parker, B. K., \& Schaal, D. W. Pavlovian facilitation by tones and centrally acting drugs: Transfer tests. Poster presented: Southeastern Association for Behavior Analysis, Charleston, South Carolina, 1995; and Northern West Virginia Chapter for Neuroscience, Morgantown, WV, 1995.

\section{Papers Presented at Professional Meetings}

Keely, J. P., Feola, T., \& Lattal, K. A. Learning Irrelevance. Paper accepted: Association for Behavior Analysis, Chicago, IL, 1999.

Keely, J. P., \& Lattal, K. A. Some Variables Controlling Avoidance of Timeout from Positive Reinforcement. Paper presented: Association for Behavior Analysis, Chicago, IL, 1997. 